\title{
The trade effects of skilled versus unskilled migration
}

\author{
CRED Research Paper No. 31
}

\author{
Peter H. Egger Maximilian v. Ehrlich Douglas R. Nelson \\ ETH Zurich University of Bern, Tulane University, \\ CRED United States
}

January 2020

\begin{abstract}
In this paper, we assess the role of skilled versus unskilled migration for bilateral trade in a flexible econometric model. Using a large data-set on bilateral skill-specific migration and a flexible novel identification strategy, the functionally flexible impact of different levels of skilled and unskilled immigration on the volume and structure of bilateral imports is identified in a quasi-experimental design. We find evidence of a polarized impact of skillspecific immigration on imports: highly concentrated skilled or unskilled immigrants induce higher import volumes than a balanced composition of the immigrant base. This effect turns out particularly important when institutions are weak. Regarding the structure of imports, we observe that skilled immigrants specifically add to imports in differentiated goods. Both bits of evidence are consistent with a segregation of skill-specific immigrant networks and corresponding trade patterns.
\end{abstract}

Key words: Skilled vs. unskilled immigration, Migrant networks, Bilateral trade, Quasirandomized experiments, Generalized propensity score estimation.

JEL classification: C14, C21, F14, F22 


\section{Introduction}

Immigration may affect trade and, in particular, imports for various reasons, of which the transaction-cost channel and the preference channel are the most prominent ones. ${ }^{3}$ Empirical work on the role of bilateral immigration for bilateral trade typically relies on three paradigms (see Gaston and Nelson, 2011; Parsons and Winters, 2014; and Felbermayr et al., 2015; for surveys of that literature): (i) that the skill structure of migration matters for the impact on trade ${ }^{4}$; (ii) that the functional form of the impact of

\footnotetext{
* Corresponding author.

E-mail addresses: egger@kof.ethz.ch (P.H. Egger), Maximilian.vonEhrlich@vwi.unibe.ch (M.v. Ehrlich), dnelson@tulane.edu (D.R. Nelson).

${ }^{1}$ CEPR, CESifo, Ifo, and WIFO.

${ }^{2}$ CESifo.

${ }^{3}$ The impact of immigration through its transaction-cost-reducing and its preference-related effects are theoretically isomorphic and empirically hard if not impossible to distinguish.

${ }^{4}$ A number of the papers on trade and migration have considered different levels of skill and found that skilled immigrants are strongly associated with trade creation, while intermediate and low levels of skill seem to have no such relationship (see Felbermayr and Jung, 2009; Hatzigeorgiou, 2010; Felbermayr and Toubal, 2012). The respective work tended to assume a (log-) linear relationship between trade and skill-specific immigration and a random assignment (i.e., exogeneity) of immigration.
}

https://doi.org/10.1016/j.jce.2019.12.008

Received 1 October 2018; Received in revised form 20 November 2019; Accepted 28 December 2019

Available online 16 January 2020

0147-5967/ (c) 2020 Association for Comparative Economic Studies. Published by Elsevier Inc. All rights reserved. 
migration on trade is linear or log-linear ${ }^{5}$; and (iii) that migration is endogenous even conditional on a linear function of other determinants of bilateral trade. ${ }^{6}$ The argument in (i) results in a heterogeneous impact of migration on trade, depending on the skillspecific composition of migration, and this impact heterogeneity is masked when using total instead of skill-specific immigration variables in explaining trade. A violation of (ii) would mean that the estimates of the trade response to migration might be meaningless to the extent that marginal changes in migration might have largely different effects on trade, depending on the level of migration in the outset. And the argument in (iii) entails that bilateral migration is not exogenous conditional on a linear function of the control variables, leading to inconsistent estimates of the relationship between migration and trade. Inter alia but not only, the latter results from a non-log-linear impact of these covariates on trade in general (see Anderson and van Wincoop, 2003; Santos Silva and Tenreyro, 2006) and a non-log-linear impact of migration on trade in particular.

This paper aims at considering the heterogeneity of the impact of skilled versus unskilled migration, the flexible nonlinearity of that relationship, and the endogeneity of each of migration by skill type through employing an econometric approach which permits considering a flexible impact of skill-specific migration on trade. This is done on the basis of a so-called generalized propensity score (GPS) framework for continuous endogenous variables (treatments; skill-specific bilateral immigration in our case) and continuous outcome (bilateral imports).

Exploiting this flexibility and using two large cross sections of bilateral stocks of skilled and unskilled immigrants and bilateral import flows for 1990 and 2000, respectively, we are able to provide novel evidence on the effect of skill-specific immigration on bilateral imports. In particular, the findings suggest that a concentration on skilled or unskilled immigrants leads to a bigger response of bilateral imports than a mixed composition of the same level of total immigration. We place this polarization result at the door of educational homophily. Hence, we interpret the findings as implicit evidence for the stronger bonding - and associated effects on trade - of networks of migrants of the same skill type. ${ }^{7}$ Moreover, an improvement of the institutional quality in a migrant's origin country displays the biggest positive effect on bilateral imports if, at the same time, the mix of immigrants is skill-wise relatively balanced.

We rationalize these findings in a number of ways, but they are consistent, in particular, with the presence of (at least partially) segmented skilled and unskilled migration networks and their effectiveness for trade in different domains of goods. Finally, the nonlinear impact of the two types of immigration on import volume and specific categories thereof suggests that the insights gained in this paper could not easily be derived in the framework of log-linear gravity equations as often used to analyze bilateral migration stocks or flows.

The remainder of the paper is organized as follows. Section 2 introduces the concept of GPS estimation with multiple (or multivariate) treatments for inference of the impact of skilled versus unskilled immigration on bilateral imports. Section 3 introduces the data used for inferences and associated descriptive statistics. Section 4 summarizes the results regarding the causal impact of bilateral skilled versus unskilled immigration on bilateral international imports, including an analysis on the structure of imports and Section 5 provides a rationalization of those findings against the background of economic theory and earlier research on the nexus between migration and trade. The last section concludes with a summary of the most important findings.

\section{Econometric approach}

\subsection{General outline}

For our purposes, we need a methodology that is able to handle two determinants of bilateral imports, namely skilled and unskilled immigration, which are (i) continuous and endogenous in case of disregarding nonlinear effects of joint determinants of trade flows and skill-specific immigration, and (ii) exhibit an impact on outcome (bilateral imports) whose functional form is unknown ex ante. In many earlier empirical studies, bilateral migration may be an endogenous regressor in the model of bilateral trade for two main reasons. On the one hand, the set of determinants of bilateral trade flows is specified in a relatively parsimonious and log-linear way so that an exclusion of joint determinants of bilateral migration and trade flows is likely, whereby bilateral migration is correlated with the residual. For instance, such a situation may root in the mis-specification of the functional form of the trade-cost function or of consumers' Armington preferences towards goods from different countries of origin. E.g., recent research suggests that the trade-cost function may be nonlinear in trade-policy variables due to the evasion of tariffs and the avoidance of other policy barriers on the part of foreign buyers (see, e.g., Fisman and Wei, 2004; Javorcik and Narciso, 2008, or Sequeira, 2016). Moreover, factor endowments (see Bombardini et al., 2012) or factor costs and average firm productivity (see Mrazova et al., 2017). Finally, percapita income as a measure of expenditures may not be proportional to imports due to an absence of goods-market clearing (see Dekle et al., 2007) or non-homothetic preferences (see Markusen, 1986). On the other hand, the functional form of the relationship

\footnotetext{
${ }^{5}$ A handful of papers considered a nonlinear functional form. See Head and Ries (1998), Wagner et al. (2002); Bryant et al. (2004) for parametric evidence and Egger et al. (2012a) for nonparametric evidence. However, the respective work focused on the impact of total rather than skill-specific immigration on trade.

${ }^{6}$ Egger et al. (2012a) permit total immigration to be endogenous in a nonparametric framework. However, that paper did not consider differential effects of skilled and unskilled immigration. Aubry et al. (2018) and Orefice et al. (2019) use an instrumental variables strategy to address the endogeneity of migration in trade equations. Ortega and Peri (2014), Alesina et al. (2016), and Egger et al. (2019) use instruments for both trade and migration to consider the effects of these two openness variables on other outcomes (such as income and income taxation).

${ }^{7}$ While transaction-cost and preference-related migration effects on trade are isomorphic, this is not true for homophily- or network-related effects. The former lead to log-linear direct effects of migration on trade whereas the latter do not. However, it is not possible to test the role of educational homophily of immigrants on imports against unknown alternatives.
} 
between bilateral migration and trade is not necessarily log-linear as is often assumed. With a log-nonlinear functional form, log bilateral migration is again correlated with the residual in the trade model which generates endogeneity.

Econometric theory offers two alternative remedies to the problem of endogeneity: instrumental-variable estimation and estimation invoking conditional mean independence. They rely on alternative catalogues of assumptions which are not nested. Specifically, instrumental variables estimation requires that instruments are relevant and they are adequate, meaning that instruments of migration are not correlated with the effect of any determinant of trade outcome which is excluded from the model. In structural nonlinear general equilibrium models of trade and migration, this assumption is unlikely met. Approaches of conditional mean independence require that all relevant determinants of (trade and) migration are included in the empirical model. The latter is more plausible in empirical models with a relatively high explanatory power, as is the case in empirical models of trade and migration.

In this paper, we illustrate that the direct impact of immigration on imports is non-log-linear, depends on the level of immigration in the outset, and the respective pattern is different for skilled and unskilled immigration.

\subsection{Model outline}

Let us denote the cross-sectional units of observation (here, country-pairs) by $i=1, \ldots, N$ and economic outcome (in the present context, the value of bilateral goods imports) by $M_{i}$. The goal of this paper is to determine the causal impact of skilled and unskilled immigration and their interaction on $M_{i}$.

For econometric identification, let us think of the levels of skilled and unskilled immigration as potentially endogenous treatments (see Egger and Ehrlich, 2013). Yet, unlike in most of the evaluation literature in econometrics, these treatments are not binary but continuous. $^{8}$

The approach in this paper relies on the following ingredients. The determination of observed levels of skilled and unskilled immigration in logs, $S_{i}$ and $U_{i}$ as a function of the joint set of determinants of skilled and unskilled immigration levels, $Z_{i}$. The latter may include country-level variables and country-pair-level variables or source- and destination-country-fixed effects and country-pair variables. In general, $Z_{i}$ may include polynomial terms of all non-binary main variables. As this is a nonlinear function of the variables, concerns with weighting are relatively minor. ${ }^{9}$ Second, the joint density of the residuals of the models of $S_{i}$ and $U_{i}$, which is called the generalized propensity score (GPS). We follow Hirano and Imbens (2005) to model this density as to be normal, here, bivariate normal. Third, a flexible model of log trade (import) outcome as a function of skilled and unskilled log immigration as well as the GPS. The latter establishes the so-called dose-response function and the treatment functions.

In particular, in this paper we will report on the average dose-response function of log imports to log skilled versus unskilled immigration. The latter informs us how, on average and conditional on a flexible form of the covariates in $Z_{i}$, imports change as either unskilled or skilled migration changes. This approach rests on two fundamental assumptions:

Assumption 1 (Weak unconfoundedness). Weak unconfoundedness as in Hirano and Imbens (2005) and Imai and van Dyk (2004) means that conditional independence - i.e., conditional on the components of $Z_{i}$, the levels of skill-specific immigration are randomized regarding import values. Hence, a particular level of skill-specific immigration depends systematically on the variables in $Z_{i}$ but the remaining part is random. This assumption is not testable.

Assumption 2 (Balancing of the covariates). The balancing of covariates is a testable assumption, and it means that the functional form of the density of the residual skill-specific immigration levels is appropriately chosen, in the sense that there is sufficient overlap between observations with different levels of immigration $S_{i} U_{i}$ but similar levels of both the covariates in $Z_{i}$ and the GPS, $G_{i}$. Hence, for all strata of the GPS the probability of the different skill-specific immigration levels does not depend on the values of $Z_{i}$. We will illustrate in Section 4.1 that the data analyzed in this paper comply with this assumption.

\subsection{Implementation and parametrization}

The implementation of the approach proceeds in five steps.

In Step 1, we estimate reduced-form parametric first-stage models determining $S_{i}$ and $U_{i}$ by ordinary least squares. The polynomial order of the terms included in $Z_{i}$ is chosen according to an information criterion (the Akaike information criterion).

In Step 2, we utilize the estimated residuals from Step 1, $\left(\nu_{S i}, \nu_{U i}\right)$, assume a functional form for the density function, namely bivariate normality, and compute the GPS as

\footnotetext{
${ }^{8}$ See Lee (2005) or Wooldridge (2010) for an extensive discussion of models with binary endogenous treatments. Also, see Lechner (2001) for econometric models with multiple binary endogenous treatments. Finally, see Hirano and Imbens (2005) or Imai and van Dyk (2004) for a generalization of propensity score estimation with univariate continuous treatments. The novelty of the approach adopted in this paper is an application of a generalization of the concept of generalized propensity scores, GPS, for multiple continuous treatments.

${ }^{9}$ Santos Silva and Tenreyro (2006) present an approach to address estimation issues with gravity models of trade, and these issues may be relevant also for migration. Specifically, they allude to a parameter bias if the true model is exponential and the stochastic term is heteroskedastic. However, they do not consider models which are functions of polynomial forms of regressors, models where trade or migration are to be determined in the first step of a two-stage regression problem, or data situations where there is a mass point at zero. Our approach involves a nonlinear index - and eventually even a nonparametric function - in the second stage, which is a problem that is not covered by Santos Silva and Tenreyro (2006).
} 


$$
\hat{G}_{i}=\frac{1}{2 \pi \hat{\sigma}_{S S} \hat{\sigma}_{U U} \sqrt{1-\hat{\rho}^{2}}} \exp \left\{-\frac{1}{2\left(1-\hat{\rho}^{2}\right)}\left[\frac{\hat{\nu}_{S i}}{\hat{\sigma}_{S S}}+\frac{\hat{\nu}_{U i}}{\hat{\sigma}_{U U}}-\frac{2 \hat{\nu}_{S i} \hat{\nu}_{U i} \hat{\rho}}{\hat{\sigma}_{S S} \hat{\sigma}_{U U}}\right]\right\}
$$

where $\hat{\sigma}_{S S}$ and $\hat{\sigma}_{U U}$ are the variances of the disturbances in the equation for $S_{i}$ and $U_{i}$, respectively and $\hat{\rho}$ is the estimated covariance between those disturbances (see, e.g., Green, 2011, for a general treatment of bivariate normals). With the treatments $S_{i}$ and $U_{i}$ measured in logarithmic terms, the normality assumption is approximately met.

In Step 3, we ensure common support, which means comparing only observations with similar levels of predicted skill-specific immigration but different realized values of skill-specific immigration. The GPS is used to select comparable units. Hence, we restrict our analysis to the common support of the estimated GPS, $\hat{G}_{i}$. With continuous treatments, we have to discretize the sample into immigration-treatment groups associated with different skill-specific immigration levels. As a benchmark, we split the data into four groups in $S_{i}-U_{i}$ space where we denote the group an observation $i$ belongs to by $Q_{i} \in\{1,2,3$, 4\}. Following Hirano and Imbens (2005), Kluve et al. (2012), and, in particular, Flores et al. (2012), who all study problems with a single continuous treatment variable, we evaluate the GPS at the median skill-specific immigration level of each group, independently of whether the observation belongs to the group or not. Only those observations that are comparable across all groups are kept for the analysis such that each observation has to fulfill the common-support criterion for all groups simultaneously. Naturally, the common-support sample depends on the number of groups we choose for the discretization. We report the analysis with four groups and note that the results are very similar when using one of nine or even sixteen groups.

Step 4 is concerned with assessing the validity of the balancing assumption. First, use again the groups in $S_{i}-U_{i}$ space as defined in Step 3. Second, we split the sample of observations within each group in $\hat{G}_{i}$-space into blocks determined by the GPS evaluated at the median treatment level of the respective group. We take observations with a similar level of GPS evaluated at the median treatment level of a group and compare each covariates between observations in and outside of the same group. This indicates whether the covariates differ significantly (i.e., are unbalanced) across groups once we condition on the GPS. Alternatively, we follow Imai and van Dyk (2004) and regress each covariate on the treatment variables with and without conditioning on the distribution of the GPS. Ideally, if the GPS absorbs all information relevant for skill-specific immigration levels, the covariates $Z_{i}$ are uncorrelated with $S_{i}$ and $U_{i}$, once we condition on the distribution of the GPS.

Step 5 pertains to estimating parametric and nonparametric regressions of the second-stage, outcome equation. The parametric model specifies the expectation of $\log$ imports conditional on $\log$ skill-specific immigration levels $E\left(M_{i} \mid S_{i}, U_{i}, G_{i}\right)$, where the vector $H_{i}$ depends on the polynomial function of the terms $\left\{S_{i}, U_{i}, G_{i}\right\}$ only (apart from a constant). We choose two alternative forms of $E\left(M_{i} \mid S_{i}\right.$ $U_{i}, G_{i}$ ), one of polynomial order which is selected by the Akaike information criterion in an ordinary least squares framework and one which is nonparametric.

The parameter estimates from this regression are neither interpretable nor of interest themselves. The reason is that $E\left(M_{i} \mid S_{i}, U_{i}, G_{i}\right)$ only represents a so-called unit-level dose-response function, where the marginal effect of $\log$ immigration levels $\left\{S_{i}, U_{i}\right\}$ depends on the level of $Z_{i}$ and $G_{i}$. What one would like to know is an average dose-response function, where the marginal effect of treatment is independent of $Z_{i}$. The latter can be obtained as follows. First, one considers the range of skill-specific immigration levels of interest. Second, one discretizes these intervals into bins on a grid and calculates all possible levels of the GPS associated with these levels. Third, one computes the average of predicted log imports for each of the grid cells in log skill-specific-immigration space. The average dose-response function is the relationship between log imports and levels of potential log skilled and unskilled immigration on the grid. We will compute the average dose-response function for a $40 \cdot 40$ grid in skill-specific-immigration space.

Both the parametric polynomial and even more so the nonparametric versions of the average dose-response function are relatively flexible and they can best be visualized graphically. The confidence bounds of the parametric and nonparametric estimators can be estimated by bootstrapping all estimation steps together, including the common-support restriction, the first-stage estimation of $\hat{G}_{i}(s, u)$, and the second-stage regressions (according to Efron and Tibshirani (1993), 200 replications should be sufficient for this).

\section{Data and descriptive statistics}

The variables entering the analysis encompass, bilateral imports, skilled and unskilled immigration stocks, and direct drivers of bilateral imports as well as direct drivers of skilled and unskilled bilateral immigration. All variables entering the analysis may be broadly grouped into dependent variables and independent variables.

\subsection{Dependent variables}

The dependent variables are bilateral import flows (which we also refer to as outcome), $M_{i}$, and bilateral stocks of skilled and unskilled immigrants (which we refer to as treatments), $S_{i}$ and $U_{i}$, respectively. The goal will be to determine the impact of (endogenous) bilateral skilled and unskilled immigration treatments on bilateral import outcome. Bilateral skill-specific immigration data are available for the years 1990 and 2000 from Docquier et al. (2009) for OECD destination countries and from Artuc et al. (2015) for non-OECD destination countries. This dictates the sample coverage of the data in the empirical analysis. We define skilled immigrants as those with at least a secondary level of education. Note that our results are invariant to an alternative aggregation with skilled immigrants characterized by at least tertiary education. As the outcome, we use data on bilateral imports from the United Nations' Comtrade Database for the average year within the period 1991-95 and 2001-05, respectively. Accordingly, we consider immigration and imports for two time periods. In order to determine the effect of immigration on the structure of imports 
Table 1

Descriptive statistics dependent variables.

\begin{tabular}{lcccc}
\hline & Mean & Std. dev. & Min & Max \\
\hline OECD residence countries & & & & \\
$\ln \left(U_{i}\right)$ & 5.977 & 2.594 & 0.000 & 15.310 \\
$\ln \left(S_{i}\right)$ & 6.725 & 2.471 & 0.000 & 14.468 \\
$\ln \left(M_{i}\right)$ & 4.647 & 3.056 & -8.517 & 12.346 \\
$M_{i}^{D} / M_{i}^{H}$ & 5.274 & 59.683 & 0.000 & 2908.723 \\
Non-OECD residence countries & 5.292 & 2.798 & & 3178 \\
$\ln \left(U_{i}\right)$ & 4.575 & 2.408 & 0.000 & 14.619 \\
$\ln \left(S_{i}\right)$ & 3.324 & 2.988 & -8.517 & 11.451 \\
$\ln \left(M_{i}\right)$ & & & 11.023 \\
\hline
\end{tabular}

Notes: We have observations for 98 countries of origin and 29 OECD countries of residence of migrants as well as 65 Non-OECD countries of residence. Countries of residence are importers of goods while countries of origin are the exporters. $U_{i}$ and $S_{i}$ refer to skilled and unskilled immigrants where we define skilled immigrants as those with at least secondary level of education. $M_{i}$ denotes total bilateral imports while $M_{i}^{D}$ and $M_{i}^{H}$ refer to differentiated and homogeneous goods imports. The classification of goods follows Rauch (1999). For most pairs with non-OECD residence countries we lack data on imports by goods classification such that we refrain from distinguishing between differentiated and homogeneous goods trade for these pairs.

we distinguish between homogeneous and differentiated goods according to the classification by Rauch (1999). We assign sectors to the respective classifications, using the Standard International Trade Classification (SITC) three-digit data. This obtains an additional dependent variable measuring the ratio between differentiated and homogeneous goods imports denoted by $M_{i}^{D} / M_{i}^{H}$.

Altogether, we cover 98 countries of origin and 29 (65) OECD (Non-OECD) countries of residence of migrants and trade between those countries in our analysis (see the Appendix for a list). Table 1 provides some descriptive features of the data on the dependent variables covered in our analysis. We measure immigration as well as imports in logarithmic terms such that our empirical analysis captures only country pairs characterized by positive values of both bilateral imports and immigration of skilled and unskilled.

In general, we follow Hirano and Imbens (2005) in discarding observations with a mass point at zero in either imports and skilled or unskilled immigration. Hence, the treatment effects should be interpreted as ones on the treated (where some immigration of either form as well as some imports exist).

\subsection{Independent variables}

As described in the previous section, we have to employ independent variables - determinants of bilateral import flows as well as of skilled and unskilled immigration stocks as elements in the vector $Z_{i}$ - in order to remove the selection bias in an assessment of the impact of the two types of immigration $S_{i}$ and $U_{i}$ on bilateral imports $M_{i}$ of country-pair $i$ (see Felbermayr and Jung, 2009; Mayda, 2010; Felbermayr et al., 2010; Felbermayr and Toubal, 2012; for important determinants of bilateral migration).

Generally, the vector of observables $Z_{i}$ includes both continuous and multi-valued discrete variables for both exporters/countries of origin and importers/countries of residence in a flexible 3rd-order polynomial functional form and binary variables in a linear functional form. ${ }^{10}$ Specifically, we include a parametric (polynomial) function of exporter/origin- and importer/residence-specific $\log$ GDP in current U.S. dollars, log GDP per capita in purchasing-power-parity terms, and log population to account for effects of economic market size, per-capita income, and population size in a fairly flexible way. These variables are taken from the World Bank's World Development Indicators 2009. Moreover, we control for origin- and residence-country GINI coefficients, unemployment rates, life expectancies, fertility rates, literacy rates, and real exchange rates between residence and origin countries as measures of unemployment risk, inequality, and economic well-being beyond per-capita income. These variables come from the World Bank's World Development Indicators 2009, the CIA World Factbook, and United Nations' Educational, Scientific, and Cultural Organization (UNESCO). Note that the just-mentioned variables are all specific to countries but do not combine any information on exporters (source countries) and importers (destination countries). To address the latter, we include (a third-order polynomial of) the following two variables that had been introduced in the trade literature by Helpman (1987): the similarity in GDP between these two countries, $S I M I_{i}=\log \left(1-\left(\frac{G D P O_{i}}{G D P O_{i}+G D P R_{i}}\right)^{2}-\left(\frac{G D P R_{i}}{G D P O_{i}+G D P R_{i}}\right)^{2}\right)$; and the absolute difference in GDP per capita as a proxy of capital-labor ratios, $R E L K L_{i}=\left|\log \left(G D P P C O_{i}\right)-\log \left(G D P P C R_{i}\right)\right|$. Clearly, these variables are highly - though not perfectly - correlated with the thirdorder polynomial terms about log GDP and log population. However, as said above, they add explanatory power by linking data of country $i$ with ones of country $j$.

Furthermore, we control for bilateral distance between residence and origin countries as a continuous pair-i-specific geographical determinant of immigration and imports as well as for common language, colonial relationship, common religion, goods-tradeagreement membership, services-trade-agreement membership, bilateral migration impediments, OECD membership, and membership in the Warsaw Pact as pair-specific binary geographical, cultural, political, and economic control variables. All geographical variables are based on information from the Centre d'Études Prospectives et d'Informations Internationales' (CEPII) geographical

\footnotetext{
${ }^{10}$ Binary variables enter linearly in order to keep the degree of multicollinearity of the model reasonably low. In general, we will use acronyms of the variables for the sake of brevity in tables. These acronyms are defined in Table 2.
} 
database. Trade agreement indicator variables as well as data on migration impediments are based on information from the World Trade Organization (WTO).

Also, we include a number of other control variables for both the country of origin and residence, capturing political and institutional factors that may be relevant for both migration and trade. First of all, we include measures of the origin- and residencespecific number of armed conflicts from the Peace Research Institute at Oslo, the corruption perception index from Transparency International, political freedom (the POLITY-IV index) from the Center for Systemic Peace (see Marshall et al., 2011), and a number of measures determining labor market features from the International Labor Organization (ILO): the bargaining power index, the working condition index, the worker discrimination index, and the child labor index. Second, we capture several dimensions of institutional quality from the World Bank's Governance Indicators. ${ }^{11}$ All time-variant covariates in $Z_{i}$ are measured prior to the endogenous variables $M_{i} S_{i}$, and $U_{i}$ in each of the two periods. ${ }^{12}$

Table 2 provides information on moments of the data for all (first-order terms of) independent variables akin to both blocks of Table 1.

\section{Results}

\subsection{Multivariate GPS estimation, common support, and the balancing property}

We include all main effects of the covariates listed in Table 2 together with quadratic and cubic terms of all non-binary regressors in the regressions explaining $S_{i}$ and $U_{i}{ }^{13}$ Altogether, there are 110 explanatory variables in the two equations when not using (sourceand destination) country-fixed effects. When using country-fixed effects, the number of regressors is reduced to 11 country-pairspecific ones.

We report parameter estimates and standard errors for the 3rd-order polynomial reduced-form-model specifications for $S_{i}$ and $U_{i}$ based on 110 regressors in Table 3 and based on 11 regressors (plus country-fixed effects) in Table 4. The coefficients are impossible to interpret due to the nonlinear form of the first-stage regressions in Table 3. However, it is generally the case with propensity score estimation that the specific parameters and marginal effects of covariates in the treatment equation(s) are of subordinate interest. What matters is that the joint contribution of the covariates to the variances of $S_{i}$ and $U_{i}$ is decently large, and that the covariates are balanced (for given estimated values of the GPS).

Indeed, the regressions do feature a decent predictive power with adjusted $R^{2}$ s of about 0.73 and 0.80 for $S_{i}$ and $U_{i}$, respectively, in Table 3 and ones of 0.76 and 0.82 in Table 4. The high $F$-statistics in the two tables point to the same conclusion. Hence, the covariates are jointly highly relevant. Models based on 1 st-order or 2nd-order polynomials would have achieved lower adjusted $R^{2} \mathrm{~s}$ of $(0.64,0.72)$ and $(0.70,0.76)$, respectively, in Table 3 . Hence, we conclude that the third-order polynomial specification in Table 3 works better than lower-order polynomial specifications and almost as well as the specifications with country-fixed effects in Table 4.

Based on the estimates in Tables 3 and 4, one may compute the GPS explicitly by assuming bivariate normality of the disturbances as in (A.2). With the treatments measured in logarithmic terms, the normality assumption is approximately met. What remains to be enforced is common support of the GPS as in Step 3 in Section 2.3, and what ought to be checked is whether the common-support assumption is tenable as outlined in Step 4 in Section 2.3. We do this for four groups (called $Q_{i}$ above) in $S_{i}-U_{i}$-space and with 16 blocks. Enforcing common support leads to a sample of 2525 observations. We illustrate the distribution of t-statistics about the equivalence of the averages of each linear term of the covariates in Fig. 1, where Panel A refers to the unconditional covariate comparison and Panel B to the comparison conditioning on the GPS.

Two insights can be gained from an inspection of Fig. 1. First, a large mass (namely $60 \%$ for the four-group common-support sample) of the t-values of unconditional comparisons lie outside of the $[-2.576,+2.576]$ interval which (approximately) indicates significance levels of less than one percent. When taking t-statistics in absolute terms, the interquartile range amounts to [1.68,6.46]. By way of contrast, only a very small mass of the distribution of t-values of conditional comparisons (on blocks of the GPS) lie outside of that interval ( 0.5 percent of the t-values are bigger than 2.576 in absolute terms). The interquartile range of absolute $t$-values for the conditional comparisons amounts to $[0.26,0.80]$. This is evident from the much more narrowly-waisted distribution of conditional-comparison t-statistics around zero relative to the unconditional-comparison t-statistics in Panels A and B of Fig. 1. Second, the mean and median values of the absolute t-statistics - which we report at the bottom of the figure - are much smaller once we condition on the GPS. For instance, among the unconditional-comparison t-statistics, the average absolute value is 4.86 and the median value is 3.30. Among the conditional-comparison t-statistics, the average absolute value is 0.60 and the median value is 0.48 . This illustrates

\footnotetext{
${ }^{11}$ While we only include covariates which are specific to one or both countries in pair $i$, it should be noted that the results are robust to the inclusion of third-country effects with regard to all of the origin- and residence-country-specific covariates on treatment (see Egger et al., 2012b, for the working paper version of this manuscript). The inclusion of the latter would serve the purpose of accounting for interdependence of origin and residence countries in supplying and attracting migrants (see Anderson, 2011).

${ }^{12}$ Trade agreement membership, corruption perception, and ILO's indices on labor market conditions are measured in 1990 and 2000 . OECD membership, geographical, cultural, historical variables, and bilateral migration impediments are time-invariant. All other elements of $Z_{i}$ are measured as averages over 1986-90 and 1996-00 for the two periods covered, respectively.

${ }^{13}$ The 3rd-order polynomial model specification is not arbitrary. We did a selection of the optimal order of the polynomial on grounds of the Akaike information criterion searching across models which involve 1st-order up to 5th-order polynomials. Based on this search, we selected the 3rd-order polynomial version as the preferred one, since no substantial decrease in the Akaike criterion could be achieved when choosing a higherorder polynomial.
} 
Table 2

Descriptive statistics independent variables.

\begin{tabular}{|c|c|c|c|c|c|}
\hline Acronyms & Description & Mean & Std. dev. & Min & Max \\
\hline$G D P R_{-} i$ & log GDP residence country & 25.504 & 1.804 & 20.789 & 29.742 \\
\hline$G D P O \_i$ & $\log$ GDP origin country & 24.770 & 2.018 & 19.859 & 29.742 \\
\hline$G D P P C R \_i$ & log GDP per capita residence country & 9.344 & 0.825 & 5.950 & 10.317 \\
\hline$G D P P C O \_i$ & log GDP per capita origin country & 8.646 & 1.142 & 5.950 & 10.317 \\
\hline$P O P R \_i$ & log population residence country & 16.451 & 1.347 & 13.400 & 20.930 \\
\hline POPO_i & log population origin country & 16.657 & 1.443 & 13.400 & 20.930 \\
\hline$G I N I R \_i$ & GINI coefficient residence country & 35.865 & 8.815 & 23.005 & 60.060 \\
\hline GINIO_i & GINI coefficient origin country & 38.631 & 9.494 & 23.310 & 67.000 \\
\hline$U N E M P R \_i$ & unemployment rate residence country & 7.824 & 4.552 & 0.030 & 27.726 \\
\hline$U N E M P O \_i$ & unemployment rate origin country & 8.366 & 5.151 & 0.030 & 27.726 \\
\hline REALEXCH_i & real exchange rate btw, residence and origin country & -0.359 & 3.716 & -21.227 & 21.538 \\
\hline$C P I R \_i$ & corruption perception index residence country & 6.235 & 2.341 & 1.600 & 9.300 \\
\hline CPIO_ $i$ & corruption perception index origin country & 4.918 & 2.320 & 1.600 & 9.300 \\
\hline ILOBARGAINR_i & ILO bargaining power index residence country & 27.440 & 16.144 & 0.000 & 50.500 \\
\hline ILOBARGAINO_ $i$ & ILO bargaining power index origin country & 25.429 & 16.179 & 0.000 & 50.500 \\
\hline$I L O L A B O R R \_i$ & ILO working condition index residence country & 34.596 & 16.235 & 0.000 & 56.000 \\
\hline ILOLABORO_i & ILO working condition index origin country & 29.149 & 16.297 & 0.000 & 56.000 \\
\hline$I L O D I S C R R \_i$ & ILO worker discrimination index residence country & 24.521 & 13.128 & 0.000 & 43.500 \\
\hline ILODISCRO_i & ILO worker discrimination index origin country & 22.339 & 13.617 & 0.000 & 43.500 \\
\hline$I L O C H I L D R \_i$ & ILO child labor index residence country & 3.359 & 4.283 & 0.000 & 12.500 \\
\hline ILOCHILDO_i & ILO child labor index origin country & 2.793 & 4.048 & 0.000 & 12.500 \\
\hline POLITY $2 R \_i$ & Polity IV index residence country & 7.445 & 4.979 & -10.000 & 10.000 \\
\hline POLITY2O_ $i$ & Polity IV index origin country & 5.026 & 6.113 & -10.000 & 10.000 \\
\hline LIFEEXPR_i & life expectancy residence country & 73.966 & 5.026 & 35.607 & 80.247 \\
\hline LIFEEXPO_i & life expectancy origin country & 69.956 & 7.743 & 35.607 & 80.247 \\
\hline FERTILR_i & fertility residence country & 2.130 & 1.020 & 1.154 & 7.720 \\
\hline FERTILO_i & fertility origin country & 2.752 & 1.496 & 1.154 & 7.720 \\
\hline$S I M I \_i$ & Similarity index & -2.218 & 1.479 & -8.640 & -0.693 \\
\hline$R E L K L \_i$ & Relative endowment index & 1.367 & 1.063 & 0.001 & 4.367 \\
\hline$D I S T \_i$ & log distance btw. residence and origin country & 8.397 & 1.013 & 4.088 & 9.891 \\
\hline$L I T R \_i$ & literacy rate residence country & 82.300 & 11.702 & 13.478 & 99.790 \\
\hline LITO_i & literacy rate origin country & 78.545 & 17.410 & 13.478 & 99.790 \\
\hline$W A R S A W \_i$ & member of Warsaw Pact & 0.029 & 0.168 & 0.000 & 1.000 \\
\hline CONFLICTR_i & number of armed conflicts residence country & 0.094 & 0.257 & 0.000 & 1.000 \\
\hline CONFLICTO_i & number of armed conflicts origin country & 0.180 & 0.331 & 0.000 & 1.000 \\
\hline$C O M L A N G \_i$ & common language in residence and origin country & 0.142 & 0.349 & 0.000 & 1.000 \\
\hline $\mathrm{COLONY} \_i$ & colonial relationship btw. residence and origin country & 0.041 & 0.199 & 0.000 & 1.000 \\
\hline$G T A \_i$ & goods trade agreement & 0.157 & 0.364 & 0.000 & 1.000 \\
\hline$S T A \_i$ & service trade agreement & 0.103 & 0.304 & 0.000 & 1.000 \\
\hline$O E C D O \_i$ & OECD member & 0.378 & 0.485 & 0.000 & 1.000 \\
\hline$R E L I G I O N \_i$ & common religion in residence and origin country & 0.271 & 0.445 & 0.000 & 1.000 \\
\hline MIGIMPED1_i & migration impediments: re-admission agreements & 0.022 & 0.146 & 0.000 & 1.000 \\
\hline MIGIMPED2_i & migration impediments: social security system & 0.214 & 0.410 & 0.000 & 1.000 \\
\hline MIGIMPED3_i & migration impediments: exchange of information & 0.176 & 0.381 & 0.000 & 1.000 \\
\hline MIGIMPED4_i & migration impediments: labor market regulation & 0.235 & 0.424 & 0.000 & 1.000 \\
\hline MIGIMPED5_i & migration impediments: respect for human rights & 0.160 & 0.367 & 0.000 & 1.000 \\
\hline GOVCCO_i & institutions origin country: control of corruption & 0.396 & 1.136 & -1.374 & 2.586 \\
\hline GOVGEO_i & institutions origin country: government effectiveness & 0.443 & 1.019 & -1.461 & 2.171 \\
\hline GOVPSO_i & institutions origin country: political stability & 0.109 & 0.947 & -2.510 & 1.668 \\
\hline GOVRLO_i & institutions origin country: rule of law & 0.296 & 1.038 & -1.728 & 1.938 \\
\hline GOVRQO_i & institutions origin country: regulatory quality & 0.465 & 0.882 & -2.098 & 2.247 \\
\hline GOVAVO_i & institutions origin country: absence of violence & 0.330 & 0.945 & -1.883 & 1.765 \\
\hline Observations & & 5117 & & & \\
\hline
\end{tabular}

Notes: We summarize information for those observations that have non-missing, positive levels of $M_{i} U_{i}$, and $S_{i}$ as well as for all covariates. When estimating the effects for subgroups of bilateral imports the respective dependent variable determines the number of observations (see Table 1).

that conditioning on the GPS is extremely powerful in the data. Conditioning on the GPS and enforcing common support substantially raises the comparability of country pairs in the dimensions of interest. Hence, we hypothesize that there is little chance that the observable variables included in the empirical model explaining $S_{i}$ and $U_{i}$ confound the impact of $S_{i}$ and $U_{i}$ on bilateral imports, $M_{i}$.

The alternative balancing test based on Imai and van Dyk (2004) and Kluve et al. (2012) supports this conclusion, as can be seen from the online appendix. Hence, we may proceed to estimate the dose-response function by means of parametric and nonparametric estimators as outlined in Step 5 of Section 2.3.

\subsection{Parametric estimates of the multivariate dose-response and treatment-effect functions}

Utilizing the GPS as a compact balancing score to reduce the endogeneity bias of $S_{i}$ and $U_{i}$ in determining $M_{i}$ by invoking the 
Table 3

First-stage estimation of GPS.

\begin{tabular}{|c|c|c|c|c|}
\hline & \multicolumn{2}{|l|}{$S_{i}$} & \multicolumn{2}{|l|}{$U_{i}$} \\
\hline & Coef. & Std.err. & Coef. & Std.err. \\
\hline Const. & $-1838.714^{*}$ & (1052.952) & $-8207.983^{* * *}$ & (892.629) \\
\hline$G D P R \_i$ & $89.709 *$ & (45.857) & $252.820^{* * *}$ & $(38.060)$ \\
\hline$G D P R_{-} i^{2}$ & $-3.416^{* *}$ & (1.728) & $-9.576^{* * *}$ & (1.431) \\
\hline$G D P R_{-} i^{3}$ & $0.042 *$ & $(0.022)$ & $0.118^{* * *}$ & $(0.018)$ \\
\hline$G D P O \_i$ & -8.897 & $(5.791)$ & 1.479 & $(4.986)$ \\
\hline$G D P O \_i^{2}$ & $0.414^{*}$ & $(0.231)$ & -0.014 & $(0.198)$ \\
\hline$G D P O \_i^{3}$ & $-0.006^{* *}$ & $(0.003)$ & -0.000 & $(0.003)$ \\
\hline$G D P P C R \_i$ & 234.677 & (384.703) & 193.388 & (306.637) \\
\hline$G D P P C R \_i^{2}$ & -24.629 & $(40.153)$ & -20.043 & $(31.969)$ \\
\hline$G D P P C R \_i^{3}$ & 0.882 & (1.398) & 0.725 & $(1.112)$ \\
\hline GDPPCO_i & 10.338 & $(7.470)$ & $10.644 *$ & $(6.368)$ \\
\hline$G D P P C O \_i^{2}$ & $-1.598^{*}$ & $(0.901)$ & $-1.547^{* *}$ & $(0.765)$ \\
\hline$G D P P C O \_i^{3}$ & $0.075^{* *}$ & $(0.036)$ & $0.070^{* *}$ & $(0.030)$ \\
\hline$P O P R \_i$ & 13.970 & $(45.420)$ & $-113.033^{* * *}$ & $(39.561)$ \\
\hline$P O P R_{-} i^{2}$ & -0.325 & $(2.728)$ & $7.236^{* * *}$ & $(2.379)$ \\
\hline$P O P R_{-} i^{3}$ & 0.001 & $(0.054)$ & $-0.145^{* * *}$ & $(0.048)$ \\
\hline$P O P O \_i$ & $-21.506^{* * *}$ & $(5.355)$ & $-24.894^{* * *}$ & (4.219) \\
\hline$P O P O \_i^{2}$ & $1.334^{* * *}$ & $(0.314)$ & $1.547^{* * *}$ & $(0.247)$ \\
\hline $\mathrm{POPO}_{-} i^{3}$ & $-0.026^{* * *}$ & $(0.006)$ & $-0.031^{* * *}$ & $(0.005)$ \\
\hline GINIR_i $i$ & $-4.512^{* *}$ & $(2.224)$ & $-19.294^{* * *}$ & (1.907) \\
\hline GINIR_i $i^{2}$ & $0.133^{* *}$ & $(0.066)$ & $0.582^{* * *}$ & $(0.056)$ \\
\hline GINIR_i $i^{3}$ & $-0.001^{* *}$ & $(0.001)$ & $-0.006^{* * *}$ & $(0.001)$ \\
\hline GINIO_ $i$ & -0.110 & $(0.138)$ & $-0.278^{* *}$ & $(0.116)$ \\
\hline GINIO_$i^{2}$ & 0.003 & $(0.003)$ & $0.006^{* *}$ & $(0.003)$ \\
\hline GINIO_ $i^{3}$ & -0.000 & $(0.000)$ & $-0.000^{* *}$ & $(0.000)$ \\
\hline$U N E M P R \_i$ & $0.584 * * *$ & $(0.098)$ & $0.811^{* * *}$ & $(0.079)$ \\
\hline$U N E M P R \_i^{2}$ & $-0.059^{* * *}$ & $(0.012)$ & $-0.094^{* * *}$ & $(0.010)$ \\
\hline$U N E M P R \_i^{3}$ & $0.002^{* * *}$ & $(0.000)$ & $0.003 * * *$ & $(0.000)$ \\
\hline UNEMPO_ $i$ & $0.245^{* * *}$ & $(0.048)$ & $0.202 * * *$ & $(0.038)$ \\
\hline$U N E M P O \_i^{2}$ & $-0.018^{* * *}$ & $(0.004)$ & $-0.013^{* * *}$ & $(0.003)$ \\
\hline UNEMPO_ $i^{3}$ & $0.000^{* * *}$ & $(0.000)$ & $0.000^{* * *}$ & $(0.000)$ \\
\hline REALEXCH_i & $0.040^{* * *}$ & $(0.015)$ & $0.028^{* *}$ & $(0.012)$ \\
\hline REALEXCH_i $i^{2}$ & -0.003 & $(0.002)$ & $-0.004 * *$ & $(0.002)$ \\
\hline REALEXCH_i $i^{3}$ & 0.000 & $(0.000)$ & 0.000 & $(0.000)$ \\
\hline SIMI_i & 0.004 & $(0.182)$ & 0.095 & $(0.144)$ \\
\hline SIMI_ $i^{2}$ & 0.039 & $(0.060)$ & 0.050 & $(0.047)$ \\
\hline$S I M I i^{3}$ & 0.004 & $(0.006)$ & 0.003 & $(0.005)$ \\
\hline$R E L K L \_i$ & $0.514^{*}$ & $(0.264)$ & $0.812^{* * *}$ & $(0.210)$ \\
\hline$R E L K L \_i^{2}$ & -0.125 & (0.199) & $-0.349^{* *}$ & $(0.156)$ \\
\hline$R E L K L \_i^{3}$ & -0.006 & $(0.036)$ & 0.034 & $(0.029)$ \\
\hline$C P I R_{-} i$ & $-12.973^{* * *}$ & $(2.368)$ & $-27.575^{* * *}$ & $(2.091)$ \\
\hline$C P I R \_i^{2}$ & $2.049^{* * *}$ & $(0.372)$ & $4.516^{* * *}$ & $(0.328)$ \\
\hline CPIR_ $i^{2}$ & $-0.101^{* * *}$ & $(0.019)$ & $-0.231^{* * *}$ & $(0.017)$ \\
\hline CPIO_ $i$ & $2.032^{* * *}$ & $(0.331)$ & $0.848^{* * *}$ & $(0.263)$ \\
\hline CPIO_ $i^{2}$ & $-0.332^{* * *}$ & $(0.063)$ & $-0.127^{* *}$ & $(0.050)$ \\
\hline $\mathrm{CPIO} \_i^{3}$ & $0.018^{* * *}$ & $(0.004)$ & $0.007^{* *}$ & $(0.003)$ \\
\hline ILOBARGAINR_i & $-0.096^{* *}$ & $(0.046)$ & -0.029 & $(0.038)$ \\
\hline ILOBARGAINR_i $i^{2}$ & 0.001 & $(0.002)$ & $-0.003^{*}$ & $(0.002)$ \\
\hline ILOBARGAINR_ $i^{3}$ & -0.000 & $(0.000)$ & $0.000^{* * *}$ & $(0.000)$ \\
\hline ILOBARGAINO_i & $-0.034^{*}$ & $(0.018)$ & -0.022 & $(0.016)$ \\
\hline ILOBARGAINO_ $i^{2}$ & $0.002^{* * *}$ & $(0.001)$ & $0.002^{* *}$ & $(0.001)$ \\
\hline ILOBARGAINO_ $i^{3}$ & $-0.000^{* *}$ & $(0.000)$ & $-0.000^{* * *}$ & $(0.000)$ \\
\hline ILOLABORR_i & $-0.150^{* * *}$ & $(0.075)$ & $-0.246^{* * *}$ & $(0.062)$ \\
\hline ILOLABORR_ $i^{2}$ & $0.008^{* * *}$ & $(0.002)$ & $0.009^{* * *}$ & $(0.002)$ \\
\hline ILOLABORR_i $i^{3}$ & $-0.000^{* * *}$ & $(0.000)$ & $-0.000^{* * *}$ & $(0.000)$ \\
\hline ILOLABORO_ $i$ & 0.015 & $(0.019)$ & $-0.035^{* *}$ & $(0.017)$ \\
\hline ILOLABORO_i ${ }^{2}$ & 0.001 & $(0.001)$ & $0.002^{* * *}$ & $(0.001)$ \\
\hline ILOLABORO_ $i^{3}$ & $-0.000^{* *}$ & $(0.000)$ & $-0.000 * * *$ & $(0.000)$ \\
\hline ILODISCRR_i & $0.166^{*}$ & $(0.097)$ & $0.140^{*}$ & $(0.081)$ \\
\hline ILODISCRR_i $i^{2}$ & -0.004 & $(0.004)$ & -0.001 & $(0.003)$ \\
\hline
\end{tabular}


Table 3 (continued)

\begin{tabular}{|c|c|c|c|c|}
\hline & \multicolumn{2}{|l|}{$S_{i}$} & \multicolumn{2}{|l|}{$U_{i}$} \\
\hline & Coef. & Std.err. & Coef. & Std.err. \\
\hline ILODISCRR_ $i^{3}$ & 0.000 & $(0.000)$ & -0.000 & $(0.000)$ \\
\hline ILODISCRO_ $i$ & $-0.037^{*}$ & $(0.021)$ & 0.020 & $(0.017)$ \\
\hline ILODISCRO_i $i^{2}$ & 0.001 & $(0.001)$ & $-0.002^{*}$ & $(0.001)$ \\
\hline ILODISCRO_ $i^{3}$ & -0.000 & $(0.000)$ & $0.000^{*}$ & $(0.000)$ \\
\hline ILOCHILDR_ $i$ & $0.777^{* * *}$ & $(0.154)$ & $1.016^{* * *}$ & $(0.132)$ \\
\hline$I L O C H I L D R \_i^{2}$ & $-0.184 * * *$ & $(0.035)$ & $-0.244 * * *$ & $(0.031)$ \\
\hline$I L O C H I L D R \_i^{3}$ & $0.010^{* * *}$ & $(0.002)$ & $0.014 * * *$ & $(0.002)$ \\
\hline ILOCHILDO_ $i$ & $0.121 *$ & $(0.068)$ & 0.034 & $(0.053)$ \\
\hline ILOCHILDO_i $i^{2}$ & $-0.033^{* *}$ & $(0.016)$ & -0.014 & $(0.012)$ \\
\hline ILOCHILDO_ $i^{3}$ & $0.002^{* *}$ & $(0.001)$ & 0.001 & $(0.001)$ \\
\hline POLITY $2 R \_i$ & -0.705 & $(0.814)$ & $1.436^{* *}$ & $(0.705)$ \\
\hline POLITY $2 R \_i^{2}$ & 0.016 & $(0.170)$ & $-0.343^{* *}$ & $(0.146)$ \\
\hline POLITY $2 R_{-} i^{3}$ & 0.003 & $(0.009)$ & $0.018^{* *}$ & $(0.008)$ \\
\hline POLITY $2 O \_i$ & -0.016 & $(0.017)$ & -0.004 & $(0.014)$ \\
\hline POLITY2O_ $i^{2}$ & 0.000 & $(0.002)$ & -0.001 & $(0.001)$ \\
\hline POLITY2O_ $i^{3}$ & $0.001 * *$ & $(0.000)$ & 0.000 & $(0.000)$ \\
\hline LIFEEXPR_i $i$ & 16.680 & (34.155) & $248.816^{* * *}$ & (28.994) \\
\hline LIFEEXPR_i $i^{2}$ & -0.248 & $(0.450)$ & $-3.311^{* * *}$ & $(0.382)$ \\
\hline LIFEEXPR_ $i^{3}$ & 0.001 & $(0.002)$ & $0.015^{* * *}$ & $(0.002)$ \\
\hline LIFEEXPO_ $i$ & $-1.766^{* * *}$ & $(0.370)$ & $-1.502^{* * *}$ & $(0.294)$ \\
\hline LIFEEXPO_ $i^{2}$ & $0.031^{* * *}$ & $(0.006)$ & $0.025^{* * *}$ & $(0.005)$ \\
\hline LIFEEXPO_ $i^{3}$ & $-0.000^{* * *}$ & $(0.000)$ & $-0.000^{* * *}$ & $(0.000)$ \\
\hline FERTILR_ $i$ & $18.510^{*}$ & (9.914) & $48.984^{* * *}$ & $(8.322)$ \\
\hline$F E R T I L R \_i^{2}$ & -7.695 & (5.407) & $-27.822^{* * *}$ & (4.532) \\
\hline$F E R T I L R \_i^{3}$ & 1.073 & (0.983) & $5.511^{* * *}$ & $(0.826)$ \\
\hline FERTILO_ $i$ & $-1.023^{* * *}$ & $(0.386)$ & $-0.781^{* *}$ & $(0.307)$ \\
\hline FERTILO_ $i^{2}$ & $0.288^{* * *}$ & $(0.101)$ & $0.203^{* *}$ & $(0.080)$ \\
\hline FERTILO_ $i^{3}$ & $-0.025^{* * *}$ & $(0.008)$ & $-0.017^{* * *}$ & $(0.006)$ \\
\hline$D I S T \_i$ & 3.659 & $(3.100)$ & 0.016 & $(3.047)$ \\
\hline$D I S T \_i^{2}$ & -0.666 & $(0.409)$ & -0.154 & $(0.395)$ \\
\hline DIST_ $i^{3}$ & $0.031^{*}$ & $(0.018)$ & 0.009 & $(0.017)$ \\
\hline LITR_i $i$ & 2.662 & (5.989) & 3.363 & (5.017) \\
\hline$L I T R_{-} i^{2}$ & -0.043 & $(0.071)$ & -0.057 & $(0.060)$ \\
\hline$L I T R \_i^{3}$ & 0.000 & $(0.000)$ & 0.000 & $(0.000)$ \\
\hline LITO_ $i$ & -0.009 & $(0.047)$ & -0.045 & $(0.036)$ \\
\hline LITO $i^{2}$ & -0.000 & $(0.001)$ & 0.001 & $(0.001)$ \\
\hline$L I T O \_i^{3}$ & 0.000 & $(0.000)$ & -0.000 & $(0.000)$ \\
\hline$W A R S A W_{-} i$ & $1.664^{* * *}$ & $(0.410)$ & $1.810^{* * *}$ & $(0.327)$ \\
\hline CONFLICTR_ $i$ & -0.473 & $(0.368)$ & $-1.101^{* * *}$ & $(0.307)$ \\
\hline CONFLICTO_ $i$ & 0.013 & $(0.096)$ & 0.027 & $(0.077)$ \\
\hline$C O M L A N G \_i$ & $0.837^{* * *}$ & $(0.110)$ & $1.174^{* * *}$ & $(0.085)$ \\
\hline COLONY_i & $1.991^{* * *}$ & $(0.164)$ & $1.602^{* * *}$ & $(0.134)$ \\
\hline$G T A \_i$ & $0.367^{* * *}$ & $(0.129)$ & $0.391 * * *$ & $(0.101)$ \\
\hline$S T A_{-} i$ & $-0.335^{* *}$ & $(0.151)$ & $-0.314^{* * * *}$ & $(0.120)$ \\
\hline$O E C D O \_i$ & $0.302 *$ & $(0.164)$ & -0.123 & $(0.126)$ \\
\hline RELIGION_i & $0.372^{* * *}$ & $(0.068)$ & $0.284 * * *$ & $(0.054)$ \\
\hline MIGIMPED $1 \_i$ & $0.686^{*}$ & $(0.385)$ & 0.300 & $(0.272)$ \\
\hline MIGIMPED2_ $i$ & 0.629 & $(0.498)$ & 0.442 & $(0.379)$ \\
\hline MIGIMPED3_i & $0.447^{*}$ & $(0.242)$ & $0.366^{*}$ & $(0.198)$ \\
\hline MIGIMPED4_ $i$ & -0.765 & $(0.476)$ & -0.443 & $(0.358)$ \\
\hline MIGIMPED5_ $i$ & $-0.552^{* *}$ & $(0.221)$ & -0.299 & $(0.183)$ \\
\hline adj. $R^{2}$ & 0.73 & & 0.80 & \\
\hline F-Stat & 68.27 & & 128.03 & \\
\hline AIC & 11,180 & & 9754 & \\
\hline Obs. & 3178 & & 3178 & \\
\hline
\end{tabular}

Notes: ***, **, * denote significance levels at 1,5 , and $10 \%$, respectively.

underlying assumptions, we present parametric dose-response-function estimates in Table 5 for the GPS based on first-stage models with and without country-fixed effects. The standard errors are estimated by a block-bootstrap procedure (with 200 replications) in order to respect two features: first, that each unit $i$ is observed in two years (1990 and 2000) so that the variance-covariance matrix may have $i$-specific blocks and, second, that the GPS $G_{i}$ is not observed but estimated by $\hat{G}_{i}$. We ensure the common-support criterion 
Table 4

First-stage estimation of GPS with country-fixed effects.

\begin{tabular}{|c|c|c|c|c|}
\hline & \multicolumn{2}{|l|}{$S_{i}$} & \multicolumn{2}{|l|}{$U_{i}$} \\
\hline & Coef. & Std.err. & Coef. & Std.err. \\
\hline WARSAW $_{i}$ & $2.426^{* * *}$ & $(0.409)$ & $2.206^{* * *}$ & $(0.319)$ \\
\hline COMLANG $_{i}$ & $0.710^{* * *}$ & (0.109) & $0.999 * * *$ & $(0.087)$ \\
\hline $\mathrm{COLONY}_{i}$ & $2.021^{* * *}$ & $(0.159)$ & $1.622^{* * *}$ & (0.131) \\
\hline RELIGION $_{i}$ & $0.402^{* * *}$ & $(0.068)$ & $0.279 * * *$ & $(0.056)$ \\
\hline $\operatorname{SIMI}_{i}$ & $-0.146^{* * *}$ & $(0.044)$ & $-0.118^{* * *}$ & $(0.035)$ \\
\hline RELKL $_{i}$ & 0.133 & $(0.107)$ & 0.082 & (0.089) \\
\hline${\text { MIGIMPED } 1_{i}}$ & $0.854 * *$ & $(0.418)$ & 0.222 & $(0.291)$ \\
\hline MIGIMPED $2_{i}$ & $1.614^{* * *}$ & $(0.561)$ & $1.218^{* * *}$ & $(0.433)$ \\
\hline MIGIMPED $_{i}$ & -0.045 & $(0.310)$ & -0.250 & $(0.253)$ \\
\hline MIGIMPED $_{i}$ & $-1.649 * * *$ & $(0.545)$ & $-0.965^{* *}$ & (0.409) \\
\hline MIGIMPED $_{i}$ & $-0.737^{* * *}$ & $(0.255)$ & -0.250 & $(0.214)$ \\
\hline adj. $R^{2}$ & 0.76 & & 0.82 & \\
\hline F-Stat & 88.34 & & 124.02 & \\
\hline AIC & 10849 & & 9583 & \\
\hline Obs. & 3,178 & & 3,178 & \\
\hline
\end{tabular}

Notes: ${ }^{* * *}, * *, *$ denote significance levels at 1,5 , and $10 \%$, respectively.

within each bootstrap replication such that the sample size may vary slightly across block-bootstrap draws.

The point estimates of the second-stage regression are not immediately informative with regard to the effect of immigration on imports. However, the significance of the terms provides information on the severeness of the endogeneity issue and the performance of the propensity score in absorbing information that determines skill-specific immigration treatment and import outcome. The main effects and interactive terms involving $\hat{G}_{i}$ are jointly highly significant (the F-statistic on all terms involving $\hat{G}_{i}$ is 14.02), which is a strong indication of selectivity across different levels of $S_{i}$ and $U_{i}$. Hence, the GPS is relevant and helps reducing the bias of the estimated response of $(\log )$ bilateral imports $\left(M_{i}\right)$ to changes in $(\log )$ bilateral immigration of the skilled $\left(S_{i}\right)$ and the unskilled $\left(U_{i}\right)$. Controlling for observable information affecting selection into treatment, we still observe that skilled and unskilled immigration have a substantial impact on imports as is evident from the joint significance of the $S$ and $U$ terms.

Note that with import outcome and skilled as well as unskilled immigration treatment, the average dose-response function is a three-dimensional object. We present the associated three-dimensional plot in the online appendix. With the parametric estimates, we choose to illustrate it in the main text by way of two-dimensional plots, one pertaining to log unskilled and one to log skilled immigrants on the abscissa. We plot the loci of the dose-response function for the 25th, 50th, and 75th percentiles of the yet other immigration treatment, respectively. In Fig. 2, we illustrate the average dose-response function for log skilled immigration in Panel A and the one for log unskilled immigration in Panel B. The $90 \%$ confidence intervals for each locus are indicated by broken lines.

A key insight from Fig. 2 is that import volume is not maximized at the diagonal where skilled and unskilled immigration reach similar levels but at the edges where the immigration stock is either dominated by skilled or by unskilled individuals. Hence, our results suggest that bilateral import flows are stimulated mostly by homogeneous immigrant communities while a heterogeneous mix between skilled and unskilled immigrants yields ceteris paribus a lower import volume. According to the results, there is a statistically significant (at 5\%) positive level of log imports for almost any form of bilateral immigration. However, Fig. 2 suggests that the import-maximizing immigration treatment corresponds to a polarization of immigrant types, irrespective of whether unskilled or skilled immigration dominates. Note that the range of observed skilled-unskilled immigration combinations does not support all of the cells in the figures. However, the polarization result is found also in the $S_{i}-U_{i}$-subspace that is supported by the data. Overall, this result is consistent with (though not a test against unspecified alternatives of) what we may call educational homophily. Hence, if immigrant networks worked more strongly within skill groups and bigger networks of migrants within skill type had a larger stimulating effect on imports, this would be consistent with what we see in the figure. The data do not support a statistically significant positive marginal effect of skilled immigration in areas where unskilled immigration dominates, and similar conclusions emerge for the opposite case i.e. for unskilled immigration in areas with predominantly skilled immigration levels.

\subsection{Nonparametric estimates of the multivariate dose-response and treatment-effect functions and general notes on the functional form}

The above results may depend to some extent on the functional form - and its potential mis-specfification - in the estimation of the average dose-response function. To avoid a bias resulting from ill-suited functional-form assumptions, we present nonparametric estimates of the average dose-response function and illustrate it in Fig. 3, again using the common-support sample with four groups as a reference point. However, it turns out that the functional form of the nonparametric function is not as smooth that two-dimensional plots can be used for illustration. Therefore, we present the corresponding results by a three-dimensional plot, akin to the one presented for the parametric function in the online appendix.

In spite of the higher degree of nonlinearity, the general u-shape around the diagonal is found again and is clearly visible in Fig. 3. Bilateral imports are maximized at either a high concentration of skilled or unskilled immigrants while a balanced mix of the two groups yields a lower level of bilateral imports. A noticeable difference to the parametric plot in the online appendix is the asymmetry 


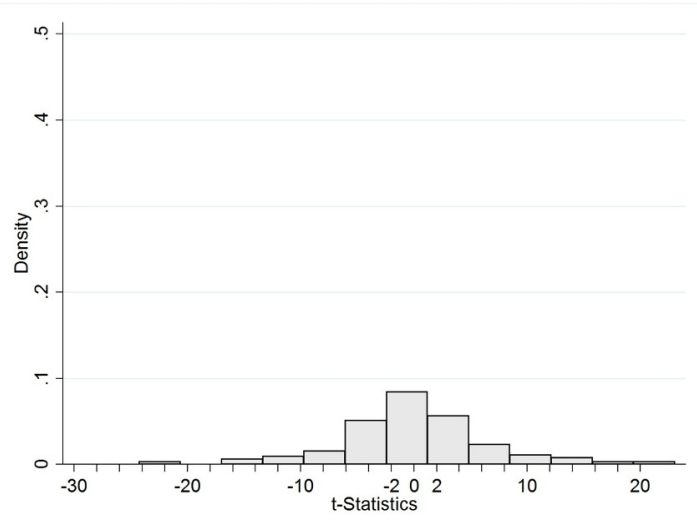

Mean: 4.86 ; Median: $3.30 ; 60 \%$ sign. at $1 \%$ level

\section{A. Unconditional}

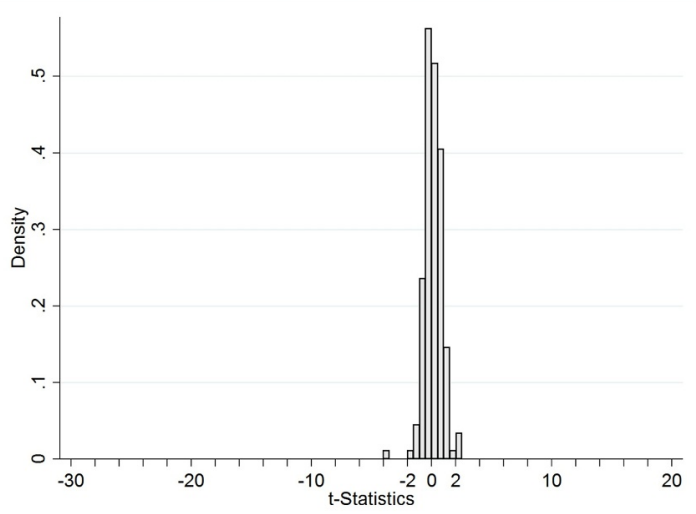

Mean: 0.60; Median: 0.48; $0.5 \%$ sign. at $1 \%$ level

\section{B. Conditional on Bivariate GPS}

Fig. 1. Balancing of Covariates - 4 Groups Note: The histograms contain the t-statistics for all 44 linear terms of the covariates. We test for the equivalence of the covariates between 4 groups which yields $176 \mathrm{t}$-statistics. In the conditional comparison we split the distribution of $\hat{G}_{i}^{q}$ into 16 blocks and conduct the t-tests for subsamples belonging to the same block. A weighted average over these blocks is computed for each treatment group and each covariate.

of the nonparametric surface at the edges with full polarization. According to the nonparametric average dose-response function, a concentration of high-skilled immigrants leads to relatively more imports than a concentration of unskilled immigrants, but we estimate for either of them a higher level of imports than at the diagonal. The evidence on the polarization is somewhat less pronounced with the nonparametric specification than with the parametric one. However, the data support is relatively weak at very extreme configurations of skilled and unskilled immigration stocks. However, the nonparametric average dose-response confirms the main qualitative parametric findings: an immigrant mix which is polarized and skewed towards either the skilled or the unskilled maximizes bilateral imports as compared to a balanced mix of skilled and unskilled immigrants.

In Table 6, we discuss some generic results regarding the appropriate functional form of the relationship of interest. To this end, comparisons of models which are log-linear, quadratic, and nonparametric - each of them with and without conditioning on the GPS - are interesting. ${ }^{14}$ We choose a tabular representation of the findings when comparing the non-overlap between the respective model predictions. The latter is based on the following procedure. For each pair among the six models in the table - of which the nonparametric one with the GPS is the most flexible one and the log-linear one without the GPS is the least flexible one - and the 1600

\footnotetext{
${ }^{14}$ We suppress fixed country-effects-based results here for two reasons. First, the adjusted $R^{2}$ of the fixed-effects estimates of the dose-response function are below the ones of the model without fixed effects. Second, the polynomial specifications of the first-stage models exhibit adjusted- $R^{2}$ figures which are only marginally lower than the ones of the fixed-effects comparison models.
} 
Table 5

Second-stage estimation of the unit dose-response function.

\begin{tabular}{|c|c|c|c|c|}
\hline & \multicolumn{2}{|c|}{ OLS } & \multicolumn{2}{|c|}{ Fixed effects } \\
\hline & $\begin{array}{c}\text { Coef. } \\
\text { (1) }\end{array}$ & $\begin{array}{l}\text { Std. err. } \\
\text { (2) }\end{array}$ & $\begin{array}{l}\text { Coef. } \\
\text { (3) }\end{array}$ & $\begin{array}{l}\text { Std. err. } \\
\text { (4) }\end{array}$ \\
\hline$U_{i}$ & $0.685^{* *}$ & $(0.229)$ & $0.878 * * *$ & $(0.209)$ \\
\hline$S_{i}$ & -0.038 & $(0.319)$ & -0.375 & $(0.292)$ \\
\hline$U_{i}^{2}$ & $0.158 * * *$ & $(0.036)$ & $0.131^{* * *}$ & $(0.038)$ \\
\hline$S_{i}^{2}$ & $0.179^{* * *}$ & $(0.053)$ & $0.216^{* * *}$ & $(0.051)$ \\
\hline$U_{i} \times \hat{G}_{i}$ & -0.115 & $(0.683)$ & 0.863 & $(0.691)$ \\
\hline$S_{i} \times \hat{G}_{i}$ & $2.777^{* * *}$ & $(0.806)$ & $1.752^{*}$ & $(0.815)$ \\
\hline$U_{i} \times S_{i}$ & $-0.350 * * *$ & $(0.083)$ & $-0.355^{* * *}$ & $(0.083)$ \\
\hline$\hat{G}_{i}$ & -4.416 & (4.498) & -5.600 & $(4.254)$ \\
\hline$\hat{G}_{i}^{2}$ & $-35.426^{* *}$ & (12.223) & $-32.387^{* *}$ & (11.393) \\
\hline Constant & 0.171 & $(0.679)$ & 1.000 & $(0.678)$ \\
\hline Observations & 2525 & & 2525 & \\
\hline adj. $R^{2}$ & 0.308 & & 0.253 & \\
\hline F-statistic $\hat{G}_{i}$ terms & 14.02 & & 13.61 & \\
\hline F-statistic $U_{i}$ terms & 11.66 & & 9.05 & \\
\hline F-statistic $S_{i}$ terms & 33.96 & & 26.50 & \\
\hline
\end{tabular}

Notes: ${ }^{* * *}, * *, *$ denote significance levels at 1,5 , and $10 \%$, respectively. Standard errors in parentheses. Specifications correspond to the common support sample with four groups. $U_{i}$ and $S_{i}$ refer to the logarithm of the stock of unskilled and skilled immigrants, respectively, who reside in the importer country and originate from the exporter country. $\hat{G}_{i}$ refers to the generalized propensity score calculated according to equation (A.2) using the coefficients from the first-stage regressions in Table 3. We estimate the standard errors of the average dose-response function by bootstrapping with 200 draws that take into account that the second-stage estimates involve imprecision from first-stage estimates.

cells in skilled-unskilled-immigration space on which the dose-response function is evaluated, we determine whether the $90 \%$ confidence intervals of the two models are overlapping or not. Then, we compute the percentage of cells among the 1600 for which the confidence intervals of two models are non-overlapping. This results in a symmetric $6 \times 6$ matrix. We provide this matrix in Table 6. The following conclusions can be drawn from this analysis. First, which is not obvious from the table, all non-log-linear models point to a polarized relationship between skill-specific (log) immigration and (log) imports. Second, among the models which include the GPS, the linear model is much more different from the quadratic one than the nonparametric is. Second, the difference between any functional form (linear, quadratic, nonparametric) with versus without the GPS is quite strong. This means that accounting for further nonlinearities by conditioning on the GPS leads to model predictions which are statistically significant in more than $20 \%$ of the cells of the dose-response function. We consider these deviations as to be large, and they underline the benefit of flexibility.

\subsection{Immigration effects on the structure of imports}

A question of interest to the matter is whether the composition of immigrants has consequences for the composition of bilateral imports. Since an investigation at the very disaggregated product level is not feasible for reasons of presentation, we resort to an analysis at the level of aggregates of product classes. A widely accepted way of grouping products is the one proposed by Rauch (1999, the so-called Rauch classification), which distinguishes between differentiated products, homogeneous products, and an intermediate category. Hence, each single observation on aggregate bilateral import flows may be split into the corresponding three sub-aggregates. Rauch (1999) offers two classification schemes, one dubbed liberal and one conservative. Since the results turn out virtually identical for the two schemes, let us focus on the liberal classification, here. Specifically, we consider the ratio between differentiated and homogeneous bilateral imports $M_{i}^{D} / M_{i}^{H}$ as an alternative outcome to total import volume. In this regard, the parametric and the nonparametric estimations yield very similar results. We provide an illustration of the corresponding findings in the online appendix and resort to a verbal discussion of the main insights here for the sake of brevity.

The results suggest that the ratio between differentiated and homogeneous goods imports, $M_{i}^{D} / M_{i}^{H}$, is unambiguously increasing in the stock of skilled immigrants, but for unskilled immigrants the opposite is true. Hence, the two types of immigrants seem to stimulate different types of bilateral imports in terms of Rauch's categories. While the aggregate level of imports ceteris paribus rises with a high concentration of either immigrant type, a high level of bilateral imports in differentiated goods seems to be facilitated by a high concentration of skilled immigrants. This evidence is consistent with the results in Rauch (1999), Rauch and Trindade (2002), Briant et al. (2009), Tai (2009), Felbermayr et al. (2010), Peri and Requena-Silvente (2010), Felbermayr and Toubal (2012), and Genc et al. (2012), who found that the share of high skilled migrants is strongly associated with imports of differentiated goods and goods traded on organized markets, but less so with goods associated with reference prices. ${ }^{15}$

\footnotetext{
${ }^{15}$ Note that the literature has focused on immigration and trade, but network effects of cross-border flows of workers and customers could also emerge due to business trips, tourism flows, etc. We follow the customary approach here of focusing on immigration, but duly note that other sources of network effects may be relevant as well.
} 


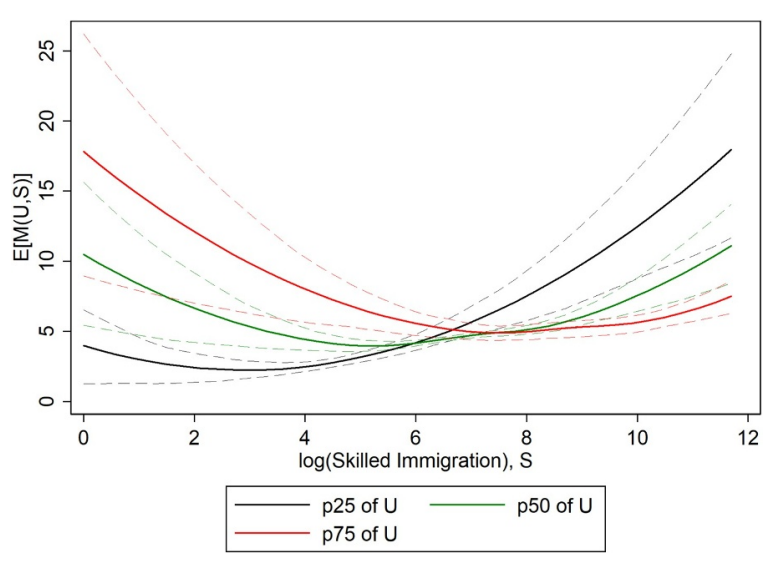

\section{A. $\log$ (Skilled Immigration)}

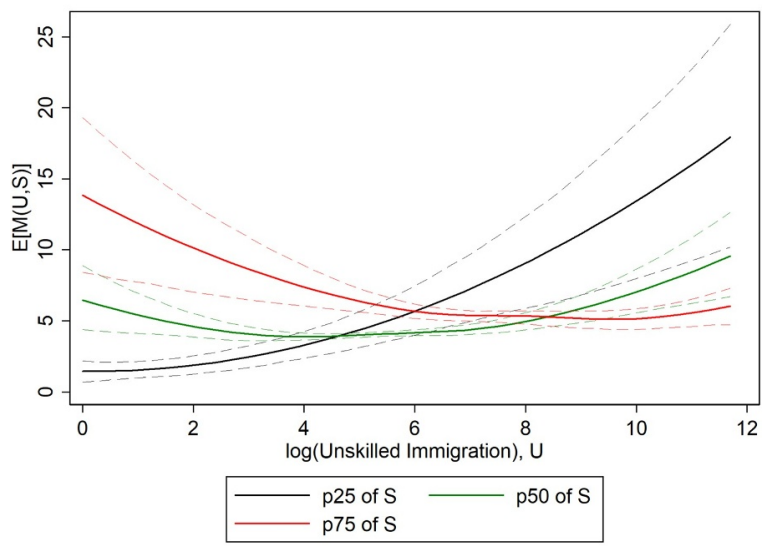

B. $\log ($ Unskilled Immigration $)$

Fig. 2. Parametric Avg. Dose-Response - Import Volume Note: Solid lines mark point estimates, dashed lines the corresponding confidence bounds (at the 95 percent level). We confidence bounds from a block bootstrapping routine with 200 replications. This routine includes the commonsupport restriction, the first-stage estimation of the GPS as well the second-stage estimation.

However, we should acknowledge that there is at least one alternative rationale for the observed impact of skill-specific immigration for differentiated versus homogeneous imports: countries with a high demand for differentiated products will likely also produce such products and, therefore, will use skilled labor intensively in production. However, this mechanism cannot explain the polarization result of skilled versus unskilled immigration and its impact on total imports. ${ }^{16}$

\subsection{Effects of migration to OECD versus non-OECD resident countries on imports}

Our benchmark estimates focus on migration from OECD and non-OECD countries of origin to OECD destination countries. Recent research by Artuc et al. (2015) made bilateral information on migration among non-OECD countries as well as migration from OECD to non-OECD countries available. The latter permits contrasting the results above with ones where the importing/residence countries are non-OECD rather than OECD economies. In doing so, we again follow the approach outlined in Section 2 in estimating the average dose-response and treatment-effect functions. For the sake of brevity, we provide the corresponding figure for the non-OECD data sample in the online appendix and summarize the insights only verbally, here.

It turns out that the predicted import response to combinations of skilled and unskilled immigrants for non-OECD residence

\footnotetext{
${ }^{16}$ Empirical work indeed suggests that the production of homogeneous, low-profit-margin goods uses unskilled workers more intensively (see Albertini et al., 2016), unskilled workers earn on average lower wages than skilled ones (Acemoglu and Autor, 2011), and low-wage earners consume homogeneous goods more intensively than differentiated ones (see Egger and Nigai, 2019).
} 


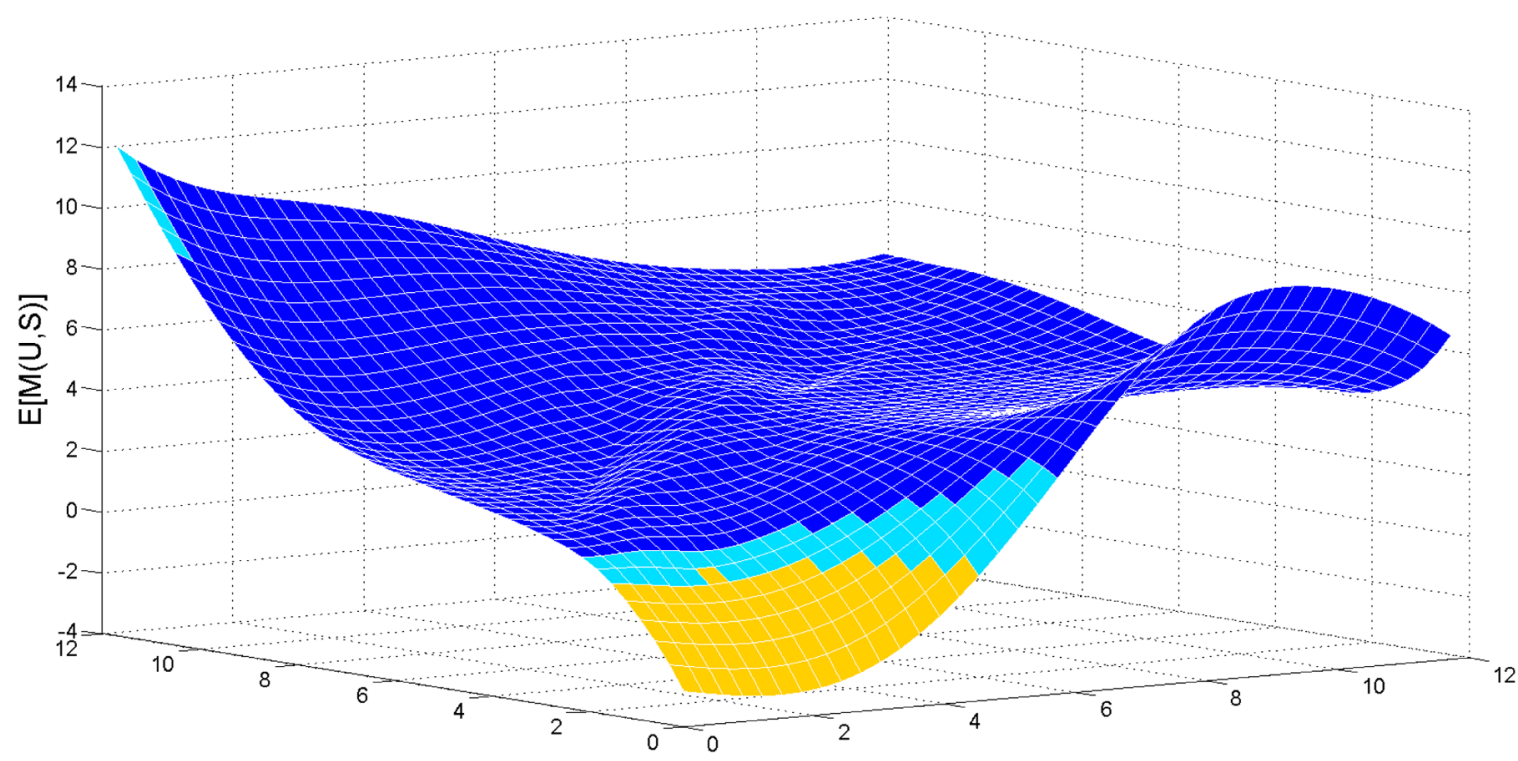

$\log ($ Skilled Immigration), S

$\log ($ Unskilled Immigration), U

Fig. 3. Nonparametric Avg. Dose-Response - Import Volume Note: Blue corresponds to significant and positive, light blue to insignificant and positive, and yellow to insignificant and negative. The surface is predicted from a multivariate local linear regression. An optimal bandwidth is obtained by cross-validation. Standard errors stem from a block bootstrapping routine with 200 replications. This routine includes the commonsupport restriction, the first-stage estimation of the GPS as well the second-stage estimation. (For interpretation of the references to color in this figure legend, the reader is referred to the web version of this article.)

Table 6

Model comparison - percentage of non-overlapping 90\%-confidence bounds across cells of the dose-response functions.

\begin{tabular}{lllllll}
\hline & $\begin{array}{l}\text { Quadratic } \\
\text { with GPS }\end{array}$ & $\begin{array}{l}\text { Linear } \\
\text { with GPS }\end{array}$ & $\begin{array}{l}\text { Nonparametric } \\
\text { with GPS }\end{array}$ & $\begin{array}{l}\text { Quadratic } \\
\text { without GPS }\end{array}$ & $\begin{array}{l}\text { Linear } \\
\text { without GPS }\end{array}$ & $\begin{array}{l}\text { Nonparametric } \\
\text { without GPS }\end{array}$ \\
\hline Quadratic with GPS & 0 & - & - & - & - & - \\
Linear with GPS & 48 & 0 & - & - & - & - \\
Nonparametric with GPS & 29 & 8 & 0 & - & - & - \\
Quadratic without GPS & 21 & 69 & 36 & 68 & 0 & - \\
Linear without GPS & 67 & 51 & 37 & 29 & 22 & 0 \\
Nonparametric without GPS & 54 & 30 & 23 & & - \\
\end{tabular}

Notes: We report the percentage of non-overlapping confidence bounds for the predicitions of the dose-response functions across six different types of models. We use 90-percent confidence bounds.

countries is very similar to the benchmark sample based on OECD residence countries. Hence, the polarized effect of immigration by skill-type on imports appears to be generic and independent of the sample of OECD versus non-OECD importing/residence-country blocks.

\subsection{Effects of immigration as well as of emigration on imports}

A further extension concerns the role of bilateral emigration (which is migration in the reverse direction of bilateral immigration). Suppose that emigrants from one country to another one engage in business activity with their country of origin. This may give rise to an additional import response which could bias the insights gained in the benchmark analysis which focused on immigration. In order to address this point, we specify total emigration as third endogenous treatment beyond $S_{i}$ and $U_{i}$ as a function of the same determinants as in Table 3, estimate the GPS, $G_{i}$, based on a trivariate normal, using the residuals of the three first-stage models, impose the common-support condition as before, and estimate the average dose-response function from a second stage model which is based on three treatments: $S_{i} U_{i}$, and log bilateral emigration (apart from the GPS). Note that this average dose-response function adjusts for potential differences of emigration across country pairs, while the one in the outset did not. However, since we are not primarily interested in the (in comparison to immigration relatively more indirect) effect of emigration on imports per se, integrate its effect out (i.e., we average over the level of emigration) and display the results for the average dose-response function in $S_{i}-U_{i}$-space as before. Clearly, while such an analysis is not informative about the impact of emigration as such, the average dose-response function for skill-specific immigration may not be biased due to an omission of emigration. We provide the corresponding illustration of the 
dose-response function in the online appendix but suppress it here for the sake of brevity.

Two observations from this analysis stand out. First, the shape of the average dose-response function and, accordingly, the polarization result remains unaffected by the consideration of bilateral emigration. Second, computing the difference of the predicted import responses with and without controlling for emigration reveals that the effect increases slightly on average. This suggests that the positive correlation between bilateral immigration and emigration leads to some mis-attribution of import responses to immigration, where emigration is the cause. However, the magnitude of the potential mis-attribution does not vary with skilled relative to unskilled immigration so that the qualitative pattern of effects is the same as in the outset.

\section{An interpretation of the polarization result of immigration on imports and some further evidence on the role of institutions}

Distinct aspects of immigration networks discussed in the literature are two: brokerage and closure. Brokerage involves building connections across groups to increase exposure to diverse opinion and practice. It is associated with growth and innovation. Immigrants are naturally brokers between their source country and the host country in which they settle (see Gould, 1994, for an early argument along those lines; the results in Head and Ries (1998); Wagner et al. (2002); Bryant et al. (2004); and Egger et al. (2012a); are consistent with this view). Closure involves strengthening connections within a group to focus the group on a limited set of opinions and practice. It is associated with trust and alignment, ultimately enhancing efficiency, and it plays a particularly central role in dealing with institutional failures and asymmetric information problems. Our results suggest that migrations characterized by a strong concentration of a given skill group will form more effective networks, generate "better" bridges, and thus produce a stronger link between migration and trade. When considering the pre-existing social bonds between any group of migrants, the claim that similarity of education creates closer bonds gains considerable plausibility. The finding that the effect of immigration on imports is stronger for immigration flows made up of people with relatively homogeneous skills is consistent with the hypothesis that the degree of closure within an immigrant community drives the network effects of trade. The role of closure, i.e., reputationbuilding and punishment via the exclusion from group benefits should be particularly pronounced for countries characterized by poor enforcement of contract and property rights. We would expect that homogeneous migrant groups exert a stronger effect on imports from countries with low quality of institutions compared to countries where the enforcement of contracts is guaranteed by an efficient legal system.

We assess this hypothesis by analyzing whether the polarization result varies with the quality of institutions as measured by indicators on the control of corruption, government effectiveness, political stability, rule of law, regulatory quality, and absence of violence which are contained in the World Bank's World Development Indicators database. Specifically, we proceed as follows to shed light on the role of institutions in conjunction with the average dose-response function in $S_{i}-U_{i}$-space. We raise each one of the justmentioned six measures of institutional quality simultaneously. Using the estimated first-stage-regression parameters, we change the residuals accordingly and give the change in institutional quality the interpretation of an exogenous, random shock. This results in an alternative level of the GPS. The latter and also all potential skilled and unskilled immigration levels together with these random shocks from the first stage are used to compute predictions based on the original second-stage regression parameters but using counterfactual values associated with raised institutional quality. Based on these, we compute the predictions for an alternative counterfactual average dose-response function, associated with the improved institutional quality. We display the difference between this parametric counterfactual average dose-response function and the original parametric one in Fig. 4. As this skill-specific-immigration-level difference is relatively nonlinear, we decided to resort to a three-dimensional representation of the dose-response function.

In the figure, blue color indicates potential skilled-and-unskilled (log-)immigration-level combinations where the predicted import response in logs is increased whereas red color indicates combinations where the predicted import response is reduced due to the higher level of institutional quality. The figure suggests that homogeneous groups of immigrants stimulate imports particularly in cases where institutions are weak in their origin countries. This is consistent with the aforementioned closure-effect hypothesis of immigrant networks.

\section{Conclusions}

This paper assesses the role of skilled versus unskilled immigration for bilateral imports in a large data-set of country pairs. Flexible parametric and nonparametric reduced-form models are postulated, where the stocks of skilled and unskilled migrants at the country-pair level are determined as endogenous continuous treatments. By invoking conditional mean independence and weak unconfoundedness, the impact of different levels of skilled and unskilled immigration on the volume and structure of bilateral imports is assessed in a quasi-experimental design. This is accomplished through a generalized estimation procedure for an assessment of causal effects of univariate continuous treatments on outcome.

Three sets of results from this analysis stand out. First, we find evidence of a polarized impact of skill-specific immigration on imports: highly concentrated skilled or unskilled migrants induce higher import volumes than a balanced, more homogeneous composition of the immigrant base. Second, while a polarization of skilled migrants seems to foster primarily differentiated goods trade, a polarization of unskilled migrants mainly stimulates homogeneous goods trade. Third, homogeneous immigrant communities tend to stimulate imports particularly strongly, where the institutions in the source (and exporting) country are weak. Either piece of evidence is consistent with a segregation of skill-specific immigrant networks and corresponding trade patterns.

This evidence has a straightforward policy conclusion. In particular, it suggests not only that trade liberalization and skill-group- 


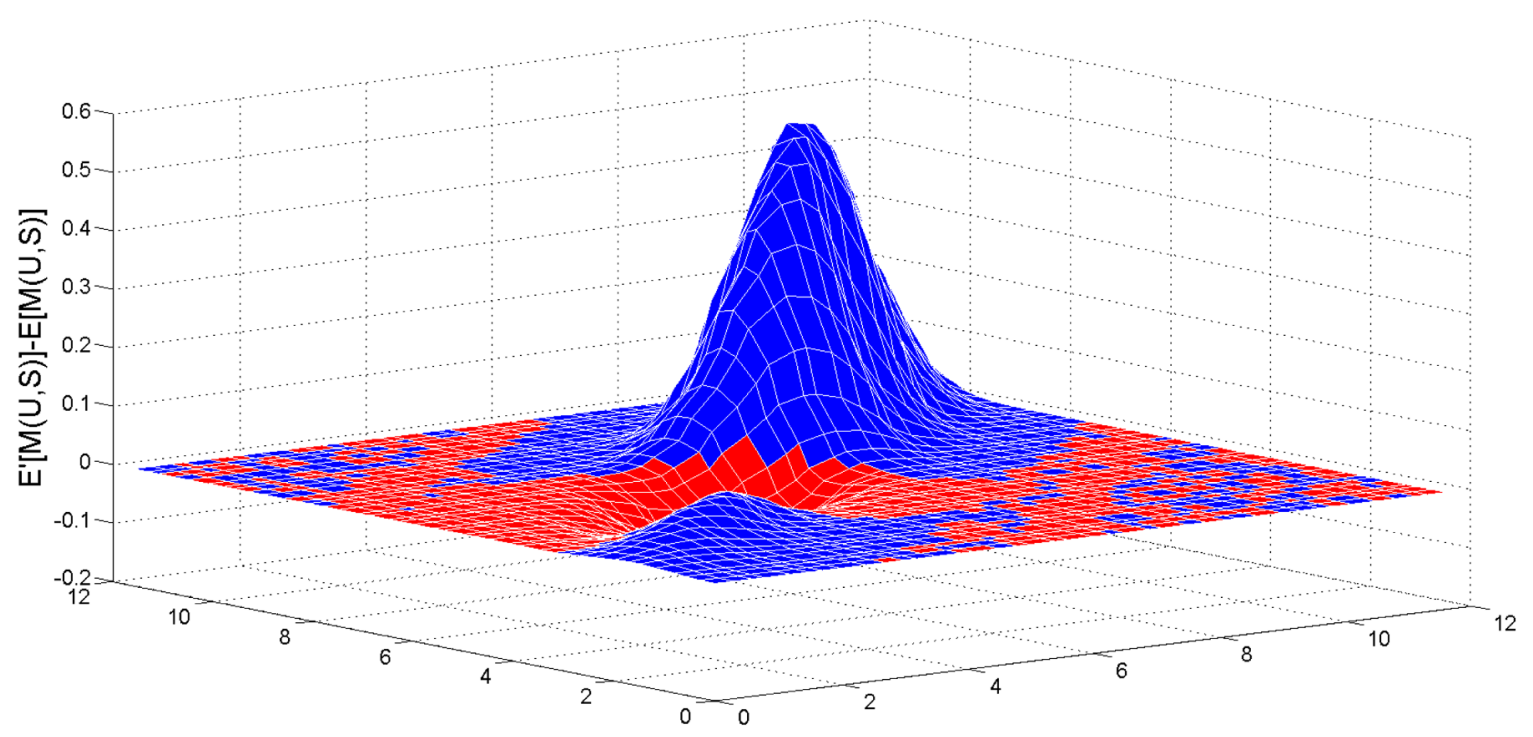

$\log$ (Skilled Immigration), S

$\log$ (Unskilled Immigration), U

Fig. 4. The Role of Institutions Note: This figure displays the difference between a counterfactual average dose-response $E^{\prime}[M(U, S)]$ function where we have raised the quality of institutions by one standard deviation and the actual average dose-response function $E[M(U, S)]$. See Section 5 for details. Both average dose-response functions are computed on the basis of the parametric version of the second-stage. We use the estimates on the control of corruption, government effectiveness, political stability and absence of violence/terrorism, rule of law, regulatory quality, and voice and accountability from the World Bank as proxies for institutional quality. We raise each of these dimensions at the same time. Hence, level of the difference $E^{\prime}[M(U, S)]-E[M(U, S)]$ reflects the gain in bilateral trade volume due to a one-standard deviation increase of institutional quality at different combinations of skilled and unskilled migration.

specific migration policy induce complementary effects on economic outcome, but it also indicates that such complementarity is stronger with regard to source and exporting countries which have weak institutions.

\section{Acknowledgments}

We gratefully acknowledge numerous helpful comments by the participants of the CEPR Workshop on the Economics and Politics of Immigration in Torino as well as the participants of the 2nd TEMPO Conference on International Migration in Vienna for numerous helpful comments. Peter H. Egger acknowledges funding by the Swiss National Science Foundation (SNSF) under grant number 00018_169537.

\section{Appendix A. Sample composition}

29 OECD residence countries: Australia, Austria, Belgium, Canada, Czech Republic, Denmark, Finland, Greece, Hungary, Ireland, Italy, Japan, Korea (Republic of), Mexico, Netherlands, New Zealand, Norway, Poland, Portugal, Slovak Republic, Spain, Sweden, Turkey, United States, Spain, Switzerland, United Kingdom.

65 non-OECD residence countries: Albania, Algeria, Argentina, Azerbaijan, Bangladesh, Belarus, Bolivia, Brazil, Bulgaria, Burkina, Cameroon, Chile, China, Colombia, Costa, Cote, Croatia, Cyprus, Ecuador, El Salvador, Estonia, Georgia, Ghana, Guatemala, Honduras, Indonesia, Israel, Jordan, Kazakhstan, Kenya, Kuwait, Kyrgyz, Latvia, Lithuania, Malaysia, Mali, Mauritius, Moldova, Mongolia, Morocco, Mozambique, Nepal, Nicaragua, Niger, Nigeria, Pakistan, Panama, Paraguay, Peru, Philippines, Romania, Rwanda, Saudi Arabia, Singapore, Slovenia, South Africa, Sri Lanka, Sudan, Thailand, Trinidad, Tunisia, Ukraine, Uruguay, Uzbekistan, Vietnam.

98 OECD and non-OECD countries of origin: Algeria, Argentina, Armenia, Australia, Austria, Azerbaijan, Bangladesh, Belgium, Bolivia, Bosnia and Herzegovina, Brazil, Bulgaria, Burkina Faso, Cambodia, Cameroon, Canada, Chile, China, Colombia, Costa Rica, Cote d'Ivoire, Croatia, Czech Republic, Denmark, Dominican Republic, Ecuador, Egypt, El Salvador, Estonia, Finland, France, Gabon, Georgia, Ghana, Greece, Guatemala, Haiti, Honduras, Hungary, India, Indonesia, Ireland, Israel, Italy, Jamaica, Japan, Jordan, Kazakhstan, Kenya, Korea (Republic of), Latvia, Lithuania, Macedonia (Former Yugoslavian Republic), Madagascar, Malaysia, Mali, Mauritania, Mauritius, Mexico, Moldova, Mongolia, Morocco, Mozambique, Nepal, Netherlands, New Zealand, Nicaragua, Niger, Norway, Pakistan, Panama, Paraguay, Peru, Philippines, Poland, Portugal, Romania, Russian Federation, Singapore, Slovak Republic, Slovenia, South Africa, Spain, Sri Lanka, Sweden, Switzerland, Tanzania, Thailand, Trinidad and Tobago, Tunisia, Turkey, Ukraine, United Kingdom, United States, Uruguay, Venezuela, Vietnam, Yemen (Republic of), Zambia. 


\section{Supplementary material}

Supplementary material associated with this article can be found, in the online version, at 10.1016/j.jce.2019.12.008

\section{References}

Acemoglu, D., Autor, D., 2011. Skills, tasks and technologies: Implications for employment and earnings. In: Card, D., Ashenfelter, O. (Eds.), Handbook of Labor Economics. 4b. pp. 1043-1171. Chapter 12.

Albertini, J., Hairault, J.-O., Langot, F., Sopraseuth, T., 2016. How do Product and Labor Market Regulations Affect Aggregate Employment, Inequalities and Job Polarization? A General Equilibrium Approach. Unpublished manuscript. TEPP - Institute of rLabor Studies and Public Policies.

Alesina, A., Harnoss, J., Rapoport, H., 2016. Birthplace diversity and economic prosperity. J. Econom. Growth 21, $101-138$.

Anderson, J.E., 2011. The gravity model. Annu. Rev. Econom. 3, 133-160.

Anderson, J.E., van Wincoop, E., 2003. Gravity with gravitas: a solution to the border puzzle. Am. Econom. Rev. 93, 170-192.

Artuc, E., Docquier, F., Ozden, C., Parsons, C., 2015. A global asessment of human capital mobility: the role of non-OECD destinations. World Dev. 65 (C), 6-26.

Aubry, A., Resheff, A., Rapoport, H., 2018. Migration, FDI and the margins of trade. Unpublished manuscript. Paris School of Economics.

Bombardini, M., Gallipoli, G., Pupato, G., 2012. Skill dispersion and trade flows. Am. Econom. Rev. 102, $2327-2348$.

Briant, A., Combes, P.-P., Lafourcade, M., 2009. Product complexity, quality of institutions and the pro-trade effect of immigrants. Paris School of Economics Working Paper \#2009 - 06.

Bryant, J., Genç, M., Law, D., 2004. Trade and migration to New Zealand. New Zealand Treasury, Working Paper Series \#04/18.

Dekle, R., Eaton, J., Kortum, S., 2007. Unbalanced trade. Am. Econom. Rev. 97, 351-355.

Docquier, F., Lowell, B.L., Marfouk, A., 2009. A gendered assessment of highly skilled emigration. Popul. Dev. Rev. 35, $297-322$.

Efron, B., Tibshirani, R.J., 1993. An Introduction to the Bootstrap. Chapman \& Hall/CRC Monographs on Statistics \& Applied Probability; London.

Egger, P.H., Ehrlich, M., 2013. Generalized propensity scores for multiple continuous treatment variables. Econ. Lett. 119, 32-34.

Egger, P.H., Ehrlich, M., Nelson, D.R., 2012a. Migration and trade. World Econ. 35, 216-241.

Egger, P. H., Ehrlich, M. v., Nelson, D. R., 2012b. The trade effects of skilled versus unskilled migration. CEPR Discussion Paper 9053.

Egger, P.H., Nigai, S., 2019. Sources of heterogeneous gains from trade: income differences and non-homothetic preferences. Rev. Int. Econom. 26, $1021-1039$.

Egger, P.H., Nigai, S., Strecker, N., 2019. The taxin deed of globalization. Am. Econ. Rev. 109, 353-390.

Felbermayr, G., Jung, B., Toubal, F., 2010. Ethnic Networks, Information, and International Trade: Revisiting the Evidence. Annales d'Economie et de Statistique. pp. 41-70.

Felbermayr, G.J., Grossman, V., Kohler, W., 2015. Migration, international trade, and capital formation: Cause or effect. In: Chiswick, B.R. (Ed.), Handbook of the Economics of International Migration. 1. pp. 913-1025. North-Holland, 2015.

Felbermayr, G.J., Jung, B., 2009. The pro-trade effect of the brain drain: sorting out confounding factors. Econ. Lett. 104, 72-75.

Felbermayr, G.J., Toubal, F., 2012. Revisiting the trade-migration nexus: evidence from new OECD data. World Dev. 40, $928-937$.

Fisman, R., Wei, S.J., 2004. Tax rates and tax evasion: evidence from missing imports in china. J. Polit. Econ. 112, 471-496.

Flores, C.A., Gonzalez, A., Neumann, T.C., 2012. Estimating the effects of length of exposure to instruction in a training program: the case of job corps. Rev. Econom. Stat. 94, 153-171.

Gaston, N., Nelson, D.R., 2011. International Migration. In: Bernhofen, D.M., Falvey, R., Greenaway, D., Kreickemeier, U. (Eds.), Handbook of International Trade. Palgrave Macmillan, Basingstoke, pp. 660-697.

Genc, M., Gheasi, M., Nijkamp, P., Poot, J., 2012. The Impact of Immigration on International Trade: A Meta-analysis. In: Nijkamp, P., Poot, J., Sahin, M. (Eds.), Migration impact assessment. Edward Elgar, Cheltenham, pp. 301-337.

Gould, D.M., 1994. Immigrant links to the home country: empirical implications for united states bilateral trade flows. Rev. Econom. Stat. 76, 302-316.

Green, W.H., 2011. Econometric Analysis. Prentice Hall, Upper Saddle River; NJ.

Hatzigeorgiou, A., 2010. Migration as trade facilitation: Assessing the links between international trade and migration. TheB.E. Journal of Economic Analysis \& Policy 10. Article 24.

Head, K., Ries, J., 1998. Immigration and trade creation: econometric evidence from canada. Can. J. Econom. 31, 47-62.

Helpman, E., 1987. Imperfect competition and international trade: evidence from fourteen industrial countries. J. Jpn. Int. Econ. 1, 62-81.

Hirano, K., Imbens, G.W., 2005. The Propensity Score with Continuous Treatments. Applied Bayesian modeling and causal inference from incomplete-data perspectives. John Wiley \& Sons, Ltd, pp. 73-84.

Imai, K., van Dyk, D.A., 2004. Causal inference with general treatment regimes: generalizing the propensity score. J. Am. Stat. Assoc. 99, 854-866.

Javorcik, B.S., Narciso, G., 2008. Differentiated products and evasion of import tariffs. J. Int. Econ. 76, $208-222$.

Kluve, J., Schneider, H., Uhlendorff, A., Zhao, Z., 2012. Evaluating continuous training programmes by using the generalized propensity score. J. R. Stat. Soc. 175, 587-617.

Lechner, M., 2001. Identification and Estimation of Causal Effects of Multiple Treatments under the Conditional Independence Assumption. In: Lechner, M., Pfeiffer, F. (Eds.), Econometric Evaluation of Labour Market Policies. 13. Physica-Verlag HD, pp. 43-58.

Lee, M., 2005. Micro-econometrics for Policy, Program, and Treatment Effects. Oxford University Press, Oxford; New York.

Marshall, M.G., Jaggers, K., Gurr, T.R., 2011. Polity IV Project: Dataset UsersManual. Center for Systemic Peace: Polity IV Project.

Mayda, A.M., 2010. International migration: a panel data analysis of the determinants of bilateral flows. J. Popul. Econ. 23, $1249-1274$.

Mrazova, M., Neary, J.P., Parenti, M., 2017. Sales and Markup Dispersion: Theory and Empirics. CEPR Discussion Paper No. 12044.

Orefice, G., Rapoport, H., Santoni, G., 2019. International Competitiveness and Migration: Diversity, Networks and Knowledge Diffusion. Unpublished manuscript. Paris School of Economics.

Ortega, F., Peri, G., 2014. Openness and income: the roles of trade and migration. J. Int. Econ. 92, 231-251.

Parsons, C.R., Winters, L.A., 2014. International Migration, Trade and Aid: A Survey. In: Lucas, R.E.B. (Ed.), International Handbook on Migration and Economic Development, Edward Elgar, pp. 65-112.

Peri, G., Requena-Silvente, F., 2010. The trade creation effect of immigrants: evidence from the remarkable case of spain. Can. J. Econom. 43, $1433-1459$.

Rauch, J.E., 1999. Networks versus markets in international trade. J. Int. Econ. 48, 7-35.

Rauch, J.E., Trindade, V., 2002. Ethnic chinese networks in international trade. Rev. Econom. Stat. 84, 116-130.

Santos Silva, J., Tenreyro, S., 2006. The log of gravity. Rev. Econom. Stat. 88, 641-658.

Sequeira, S., 2016. Corruption, trade costs, and gains from tariff liberalization: evidence from southern africa. Am. Econom. Rev. 106, $3029-3063$.

Tai, S.H.T., 2009. Market structure and the link between migration and trade. Rev. World Econom. 145, 225-249.

Wagner, D., Head, K., Ries, J., 2002. Immigration and the trade of provinces. Scott. J. Polit. Econ. 49, 507-525.

Wooldridge, J.M., 2010. Econometric analysis of cross section and panel data. MIT Press, Cambridge, Mass. 


\section{Center for Regional Economic Development (CRED)}

University of Bern

Schanzeneckstrasse 1

P.O.Box

CH-3001 Bern

Telephone: +41316313711

E-Mail: info@cred.unibe.ch

Website: http://www.cred.unibe.ch

The Center for Regional Economic Development (CRED) is an interdisciplinary hub for the scientific analysis of questions of regional economic development. The Center encompasses an association of scientists dedicated to examining regional development from an economic, geographic and business perspective.

\section{Contact of the authors:}

Peter H. Egger

ETH Zurich

Leonhardstrase 21

CH-8092 Zürich

Telephone: +41446324108

Email: egger@kof.ethz.ch

Maximilian von Ehrlich

University of Bern

Schanzeneckstrasse 1

P.O.Box

CH-3001 Bern

Telephone: +4131631 8075

Email: maximilian.vonehrlich@vwi.unibe.ch 
Douglas R. Nelson

Tulane University

108 Tilton Hall

New Orleans, Louisiana 70118-5698 USA

Telephone: +1 (504) 865-5317

Email: dnelson@tulane.edu

This paper can be downloaded at:

https://www.cred.unibe.ch/forschung/publikationen/cred_research_papers/index_ger.html 